\title{
Los Helechos: elementos esenciales en la conservación de nuestra flora
}

\author{
Antonio Manuel Escámez Pastrana
}

Iconografía del Autor

\section{Introducción}

Dentro del fascinante mundo de los vegetales, existe un grupo de plantas que no poseen flores ni semillas aunque presentan esporangios, frecuentemente agrupados, que originan esporas; tienen un sistema vascular bien desarrollado, el tallo en general en forma de rizoma y a menudo las hojas (frondes) muy divididas. Estas plantas son conocidas en sentido amplio, como helechos y constituyen la División Pteridophyta del Reino Vegetal, grupo que es el menos numeroso de dicho Reino y en el que se integran unas 12.000 especies -distribuidas mayoritariamente en las zonas intertropicales-, de las que al menos el $10 \%$ son especies sobre las que incide algún tipo de amenaza.

Los pteridófitos (del griego pteris, helecho) como grupo heterogéneo y polimorfo y a su vez el más primitivo de las plantas vasculares, con una dilatada historia evolutiva que se prolonga hasta los tiempos actuales con progresivos procesos microevolutivos centrados básicamente en anomalías meióticas que permiten procesos de hibridación y poliploidia, constituyen un conjunto de líneas evolutivas que han seguido una evolución paralela y alcanzado niveles de complejidad comprables.

En este diverso grupo se incluyen los "licopodios" (Cl. Lycopsida), las "colas de caballo" (Cl. Equisetopsida), los "helechos escoba" (Cl. Psilotopsida) y, finalmente los "helechos verdaderos" (Cl. Ophioglossopsida y Cl. Filicopsida), además de otras formas fósiles extintas; todas ellas determinadas por un patrón biológico común: nivel de organización cormofítico, vascularización, reproducción por esporas producidas por esporangios agrupados o solitarios y alternancia de generaciones independientes con predominio de la generación esporofítica (generación diploide foliosa) frente a la generación gametofítica (generación haploide más o menos foliáceo-taloidea, más raramente maciza y en escasísimas ocasiones vascularizada y caulinar).

De entre todos los vegetales evaluables de la flora de una región determinada, los helechos cobran especial protagonismo por varias e importantes razones que justifican la dedicación que les han ofrecido numerosos y relevantes científicos de todo el mundo, quienes han intentado a lo largo de la historia de la Botánica -que es casi como decir a lo largo de la historia de la humanidad-, pero en especial a partir del presente siglo, profundizar y conocer la biología de estas plantas, siendo en la actualidad uno de los grupos vegetales mejor conocidos, con una sistemática bastante coherente basada en el reflejo de su amplia historia filogenética, que no por amplia ha dejado de ser 
relativamente bien estudiada. Sin embargo, aún hoy la situación taxonómica de géneros y familias de pteridófitos es ciertamente fluctuante y queda expresada desde variadas perspectivas, debido a la complejidad inherente al grupo.

Según todo lo anterior, no sería demasiado complicado enumerar algunas de las razones más sobresalientes que confieren a los helechos esa singular importancia en el mundo de las plantas, entre otras:

-Es un grupo vegetal muy antiguo y de gran valor científico y didáctico en los estudios relativos a la evolución y filogenia de las plantas vasculares en general.

-Entre sus especies incluyen un elevado número de relictos, especies relegadas en albergues puntuales muy localizados y que en otro tiempo tuvieron una amplia distribución, constituyendo así el testimonio de una vegetación ancestral.

-Su presencia suele estar ligada a ecosistemas muy particulares cuya fragilidad evidencia su necesaria protección y conservación.

-Un gran número de sus especies están sufriendo actualmente diversas presiones que amenazan su futura pervivencia.

Argumentos como los citados justificaron la puesta en marcha del "Plan para la Protección de los Pteridófitos", propuesto a finales de 1986 por la IAP (International Association of Pteridologists), asociación encuadrada dentro de la Comisión para la Supervivencia de las Especies de IUCN (International Union for Conservation of Nature and Natural Resources).

Pero desde mucho tiempo antes era ya conocida la trascendencia de los helechos, que se fue haciendo más patente durante todo este siglo, comenzando quizá con el gran auge de la pteridología internacional promovido por anatomistas, morfólogos y paleontólogos de finales del pasado siglo, quienes encontraron sus estudios recogidos en la síntesis de ENGLER \& PRANTL Die natürlichen Pflanzenfamilien (1898-1902), proyecto enciclopédico en el que quedó plasmada la complejidad taxonómica de este grupo de plantas entre las que los fósiles representan una importante parte. A destacar también las investigaciones de BOWER, con el trabajo de 30 años condensado en su obra The Ferns (Filicales), treated comparatively with a view to their natural classifcation (1923-1928); de este autor PICHI SERMOLLI (1972) llegó a decir que "probablemente ningún otro pteridólogo contribuyó en tanta medida como BOWER a nuestro conocimiento sobre la filogenia de los helechos". Pero tal vez uno de los pilares decisivos en el fomento de la pteridología moderna haya que buscarlo en la obra de MANTON Problems of cytology and evolution in the Pteridophyta (1950), a partir de la cual se marcan las pautas de investigación pteridológica para numerosos autores europeos que comienzan a indagar en los procesos de especiación de los helechos, deteniéndose especialmente en el descifrado de los sucesos microevolutivos y fomentando numerosos estudios taxogenéticos en varios géneros y familias.

El creciente cúmulo de datos y resultados provocaría la necesidad de recopilación, síntesis y ordenación de este extenso conocimiento de los pteridófitos. Así aparecieron en 1977 dos síntesis de gran interés: Cytotaxonomical Atlas of the Pteridophyta de LOVE, LOVE \& PICHI - SERMOLLI y Tentamen pteridophytorum genera in taxonomicum ordinem redigendi de PICHI-SERMOLLI.

La base científica edificada por estos ya clásicos autores en pteridología, ha permitido que esta ciencia botánica pueda verse enriquecida en la actualidad por las ten- 


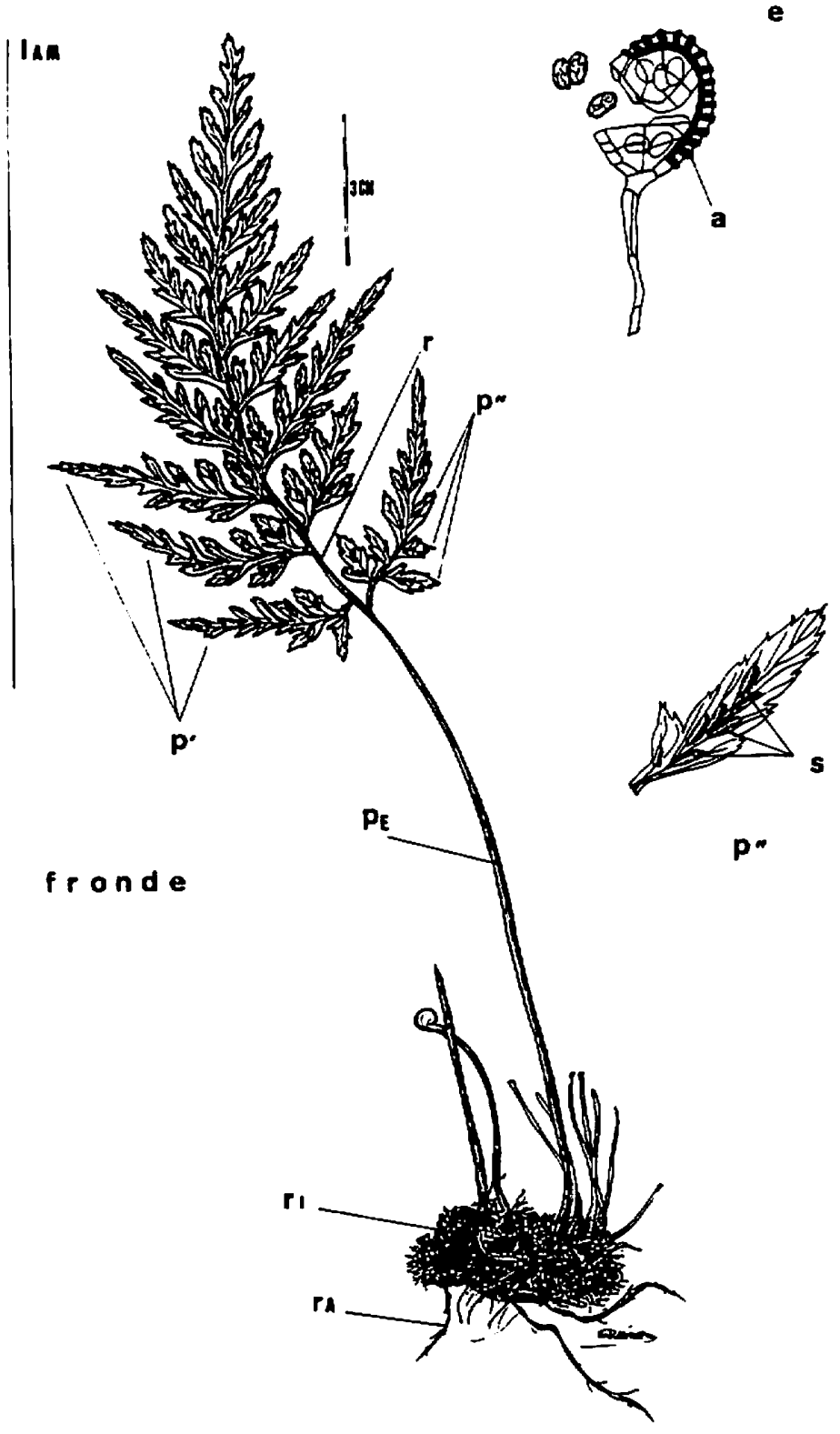

\section{LAMINA 1}

Asplenium onopteris $\mathbf{L}$.

Fronde del helecho donde se señalan la lámina (LAM), las pinnas o divisiones de primer orden ( $p$ '), las pínnulas o divisiones de segundo orden ( $p$ ') y el raquis ( $r$ ), además del peciolo (PE) y el rizoma (rI) provisto de raíces (rA).

e, esporangio; a, anillo de esporangio.

p", pínnula, s, soros. 
dencias renovadoras de los pteridólogos modernos, quienes en los últimos años han impulsado múltiples y diversas investigaciones filogenéticas y taxonómicas en general, desarrollándose estudios morfológicos, anatómicos e histológicos, esporopalinológicos, (como muestra véase Lámina 2), genéticos a nivel cromosómico y molecular, fisiológicos relativos al comportamiento en el ciclo de vida y a las pautas ecofisiológicas de los táxones en los ámbitos autoecológicos y sinecológicos, además de los tradicionales, inevitables y necesarios estudios florísticos.

Aunque lo cierto es que estos planteamientos de estudio determinan de hecho la estructura general de la investigación pteridológica contemporánea, no obstante es una estructura imperfecta (porque está inacabada) y dinámica (porque está abierta a otras tendencias) que va progresando con nuevas propuestas de los pteridólogos de hoy, como lo demuestran las innovaciones en lo relativo a la evolución del ADN cloroplástico, a la aplicación de métodos numéricos en los análisis pteridofíticos integrales o a las técnicas de propagación in vitro. 


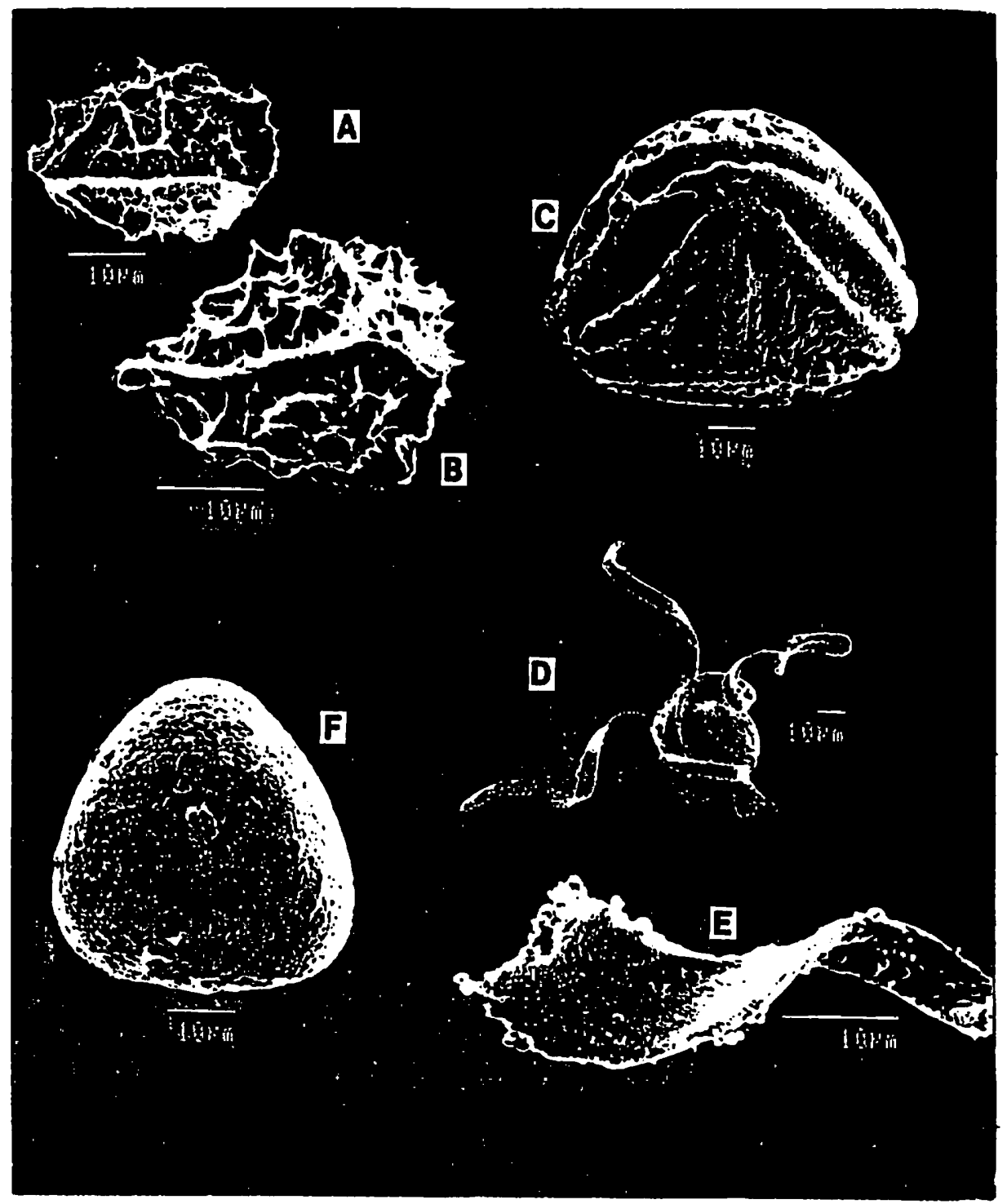

\section{LAMINA 2}

Visión tridimensional de la superficie de las esporas de algunos pteridófitos que viven en el Gurugú, utilizando el Microscopio Electrónico de Barrido (MEB).

A y B, Asplenium onopteris L., (dos esporas a distintos aumentos).

C, Cosentinia vellea (Aiton) Tod.

D, Equisetum telmateia Ehrh., E. detalle de la extremidad de un eláter.

F, Adiantum capillus-veneris L.

Fotografías del autor.

Palinoteca del Dpto. de Biología Vegetal de la Universidad de Málaga (MGC). 

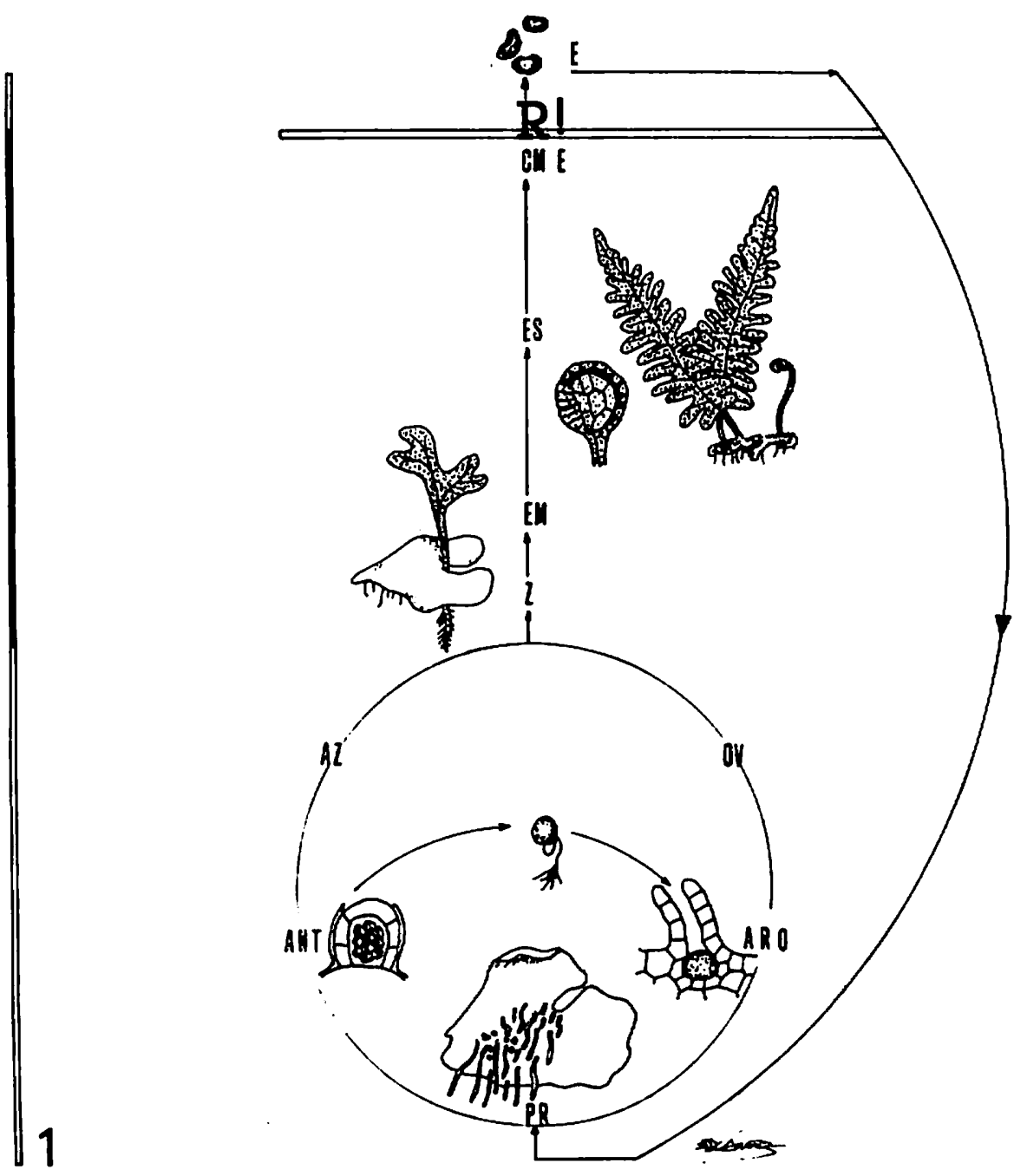

\section{LAMINA 3}

1. Representación esquemática del ciclo biológico de un pteridófito isospóreo. (Modelo Polypodium cambricum L.).

PR, prótalo (gametofito); ANT, anteridio; ARQ, arquegonio;

$A Z$, anterozoide; OV, ovocélula; Z, zigoto; EM, embrión;

ES, esporófito (helecho folioso) productor de esporangios;

CME, célula madre de las esporas, $E$, espora. 


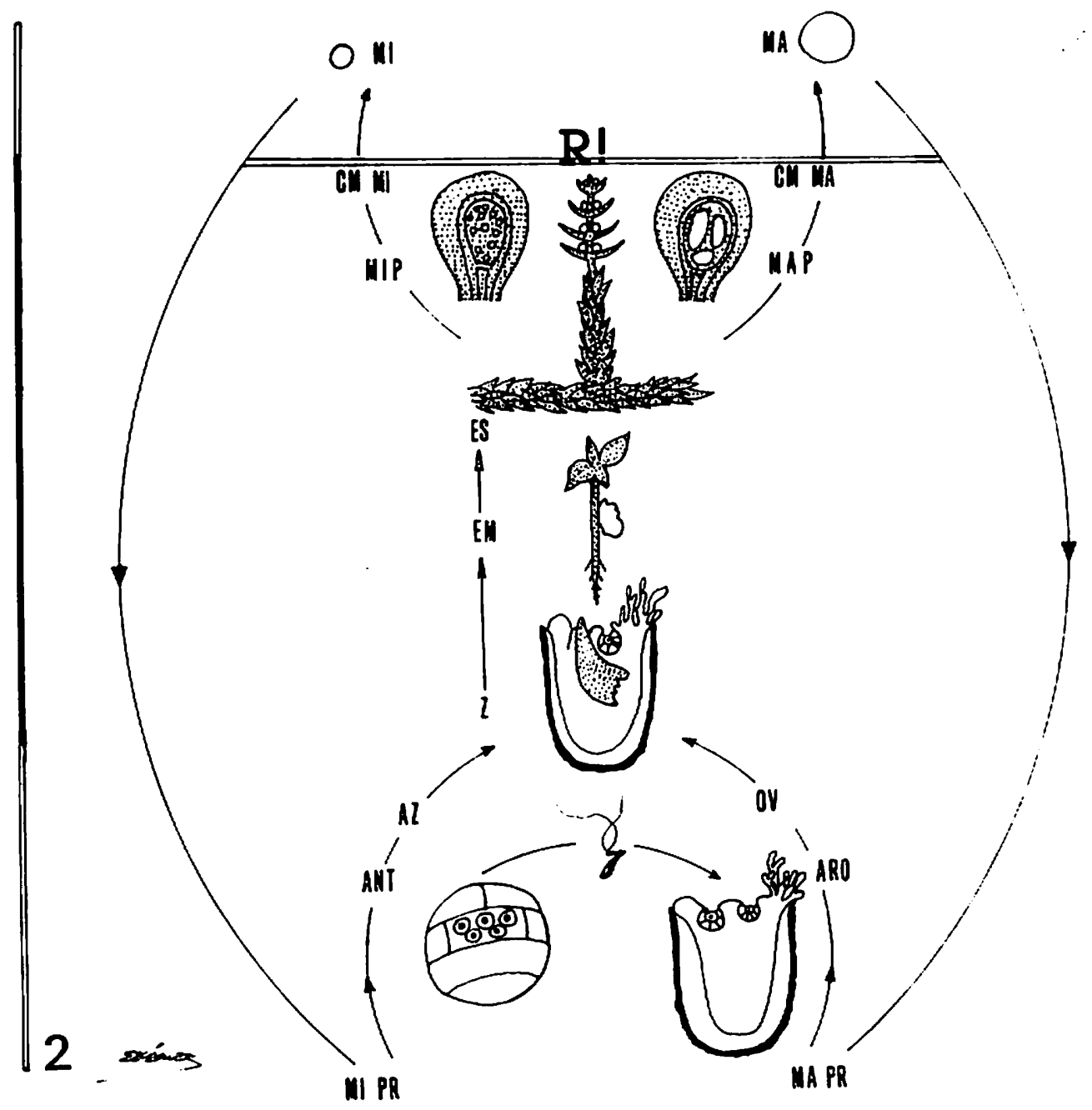

2. Representación esquemática del ciclo biológico de un pteridófito heterospóreo. (Modelo Selaginella denticulada (L. Spring).

MI PR, microprótalo (microgametófito) reducido dentro de la micróspora; MA PR, macroprótalo (macrogametófito) reducido dentro de la macróspora; ANT, anteridio; ARQ, arquegonio; $\mathbf{A Z}$, anterozoide; $\mathrm{OV}$, ovocélula; Z, zigoto; EM, embrión al principio unido al gametófito; ES, esporófito (pteridófito folioso); MIP, microsporófilos productores de microsporangios; MAP, macrosporófilos productores de macrosporangios; CM MI, célula madre de las micrósporas; CM MA, célula madre de las macrósporas; MI, micróspora; MA, macrospora.

En ambos modelos, $\mathbf{R}$ ! expresa Meiosis (división reduccional) y para cada uno de los ciclos, la línea situada a su izquierda indica el nivel ploídico: en trazo negro fase diploide (2n) (las estructuras diploides aparecen con el fondo punteado en los dibujos) y en trazo blanco fase haploide (n) (las estructuras haploides aparecen con el fondo blanco en los dibujos). 


\section{Los helechos en el escenario histórico-biogeográfico mediterráneo}

Para llegar a comprender como conjunto al grupo vegetal de los helechos, se hace necesaria una visión de su pasado, de su historia evolutiva. Por otra parte debe también tenerse en cuenta que la distribución biogeográfica actual de estas plantas en amplios y estabilizados areales, ha estado determinada por los acontecimientos geológicos y climáticos acaecidos en el planeta a lo largo de su dilatada historia y por las posibilidades colonizadoras de éstos en zonas más o menos amplias, con los condicionamientos óptimos para su desarrollo.

Un sobrevuelo por el pasado de los pteridófitos es, por tanto, una cuestión trascendente si se quiere conocer para una región determinada, su epiontología o génesis de su flora. Cuando esta región es una zona de la Tierra tan compleja, singular, caprichosa ... y apasionante como la región mediterránea, esa cuestión trascendente se toma en condición sine qua non.

\section{Algo sobre la historia evolutiva de los helechos}

Para encontrar el origen de los pteridófitos, quizá haya que recorrer en el tiempo hasta 430 millones de años atrás o probablemente incluso más 1 .

La información extraída de los estudios paleobotánicos realizados hasta el momento, sitúa a las primeras plantas vasculares entre finales del Ordovícico y el Silúrico medio. Su diversificación posterior a lo largo del Silúrico y durante el Devónico fue rápida y extensa, quedando ya entonces diferenciados los distintos grandes grupos que integran hoy la División Pteridophyta.

El período de mayor esplendor de los helechos en el planeta coincidió con el Carbonífero, transcurridos desde entonces hasta nuestros días unos 300 millones de años, cuando se extendian sobre la Tierra grandes y exhuberantes bosques de helechos arborescentes de cuya existencia queda hoy el vestigio de los yacimientos de carbón. A lo largo de todo este tiempo de progreso biológico en los pteridófitos, muchos grupos surgieron y desaparecieron después, no estando representados actualmente entre la pteridoflora viva. Así el Pérmico supuso para los pteridófitos la desaparición de muchos de sus grupos, particularmente de las formas arborescentes, al tener lugar un cambio climático tendente a la disminución de la humedad que imperaba durante el Carbonífero, mientras las gimnospermas, que surgieron a finales de este período, encontraron a lo largo del Pérmico las condiciones apropiadas para su expansión, desplazando en general a los pteridófitos durante el Jurásico, período que asiste en sus postrimerías a la aparición de las angiospermas.

El Cretácico supone para los helechos la realidad del lento derrumbamiento de las antiguas líneas filogenéticas que lograron continuar su andadura evolutiva hasta llegar a la actualidad, en un mundo dominado por los espermatófitos, plantas con semilla.

(1) Para profundizar en este tema, véase SALVO, A.E.; A. FLORES \& A.M. ESCAMEZ. 1989. El Origen de los Comófitos. Transmigración y Colonización terrestre. Publicaciones de la UNED de Melilla $\mathbf{n}^{\circ}$ 12. 

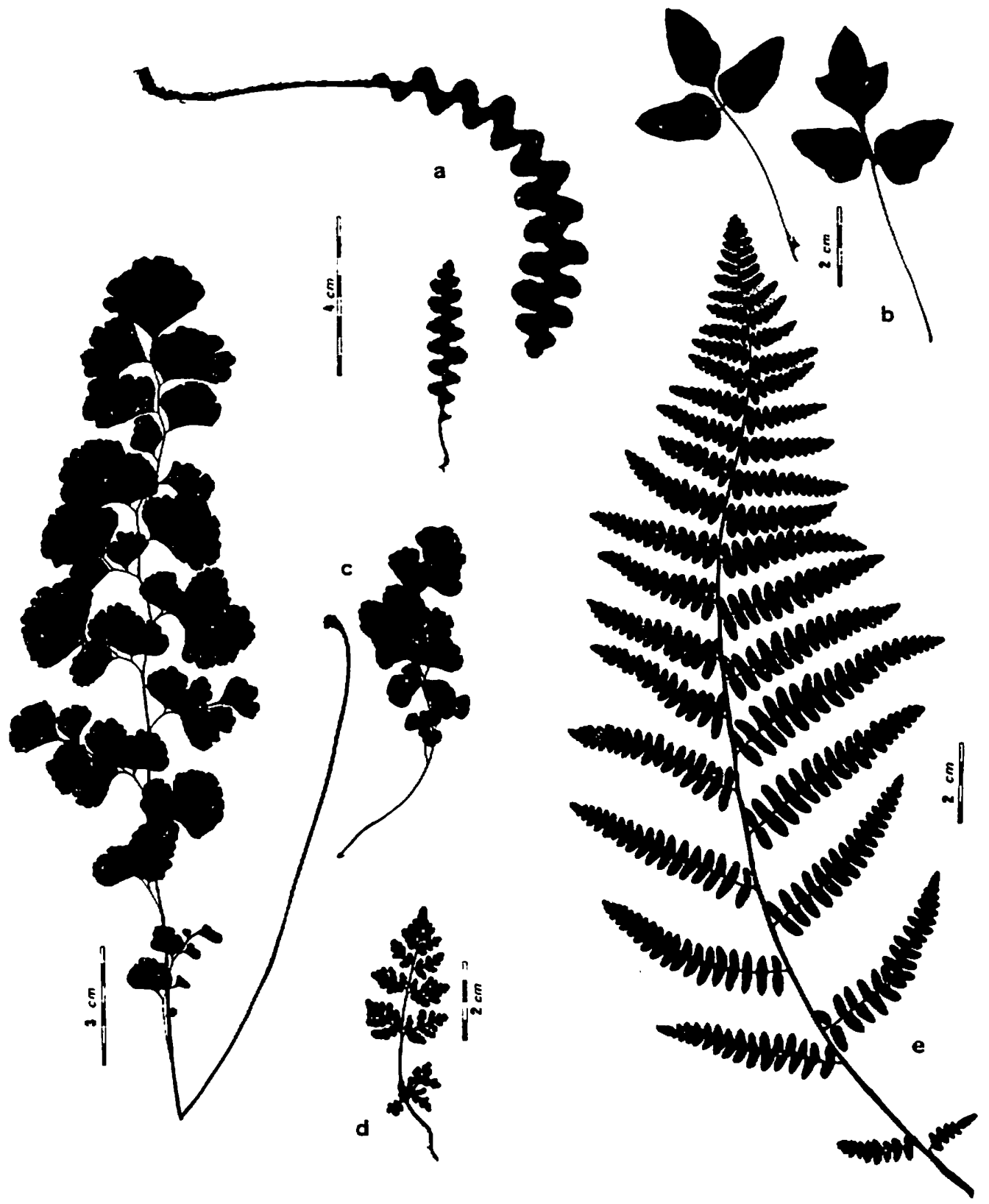

\section{LAMINA 4}

Helechos del Gurugú.

a, Asplenium ceterach L. (“doradilla”); b, jóvenes plántulas de Osmunda regalis L. ("helecho real"); c, frondes de Adiantum capillus-veneris L. ("culantrillo de pozo"); d, Cheilanthes maderensis Lowe, e, aspecto de una división de primer orden de Pteridium aquilinum (L.) Kuhn ("helecho águila"). 
Los helechos representan hoy un conjunto bastante reducido de plantas que abundaron en otros tiempo y en cuyo devenir histórico quedaron integrados grandes episodios de la evolución general del mundo vegetal, como la vascularización de su cuerpo para la vida en las tierras emergidas o el surgimiento de los espermatófitos.

La profundización en el conocimiento del origen y de los rumbos filéticos adoptados por los helechos, no sólo permite verter luz sobre los oscuros pasajes de su pasado, sino que además es el requisito imprescindible para la fijación de su controvertido y fluctuante ordenamiento sistemático.

Un gran número de antiguos y actuales autores, taxónomos y sistemáticos del Reino Vegetal, han publicado numerosos trabajos basados en especulaciones acerca del papel de los pteridófitos en la evolución de las plantas superiores, adoptando como argumento de discusión los datos aportados por los estudios y comparaciones de tipo morfológico realizadas. En general, los citogenetistas han contribuido relativamente en escasa medida a la dinámica de esa discusión, si bien los cromosomas y su comportamiento en el ciclo biológico de los pteridófitos, ofrecen una perspectiva más amplia para el seguimiento de su evolución que los indicios registrados por algunas tendencias morfológicas.

Cuestión aparte digna de mención, es el hecho de que los procesos meióticos en Lycopsida, Equisetopsida y Psilotopsida son considerablemente más semejantes a los de Spermatophyta que a los de Filicopsida, mientras ciertas condiciones citogenéticas ausentes para todos los pteridófitos están presentes en algunos representantes de Monocotyledonopsida y grupos de algas verdes, indicando un posible origen polifilético y una demostrada y patente construcción artificiosa de esta clase.

Nuevas, sucesivas y detalladas investigaciones citogenéticas podrán revelar que los distintos táxones superiores en Pteridophyta probablemente pertenezcan a varias líneas que llegan a conectar con diferentes órdenes de Spermatophyta, manifestándose así que el "tronco monofilético común" de las plantas superiores, en realidad pudo extenderse considerablemente siguiendo extraordinarias desviaciones a lo largo del esquema que debiera plasmar la situación como originalmente debió ser.

\section{Las tierras mediterráneas}

¿Cómo elegir un calificativo que pueda definir la realidad natural de la región mediterránea?

La propuesta es difícil; muchas y diversas son las características y peculiaridades que contribuyen a la idiosincrasia mediterránea, pero quizás todas estén vinculadas a una condición común: el carácter de encrucijada que esta tierra posee.

La encrucijada en la región mediterránea permitió la inclusión de tierras extratropicales que estuvieron unidas a finales del Cretácico en el continente Noratlántico o Laurasia, es decir, permitió el nexo entre floras gondwánicas y laurásicas y el tránsito migratorio entre el Norte y el Sur, constituyendo en muchos casos el refugio de las especies que iban relegándose hacia el Sur como consecuencia de las glaciaciones del Cuaternario, o de táxones procedentes de regiones de mayor xeracidad que ensayaron distintos avances hacia latitudes más septentrionales cuando las condiciones pudieron permitirlo. 


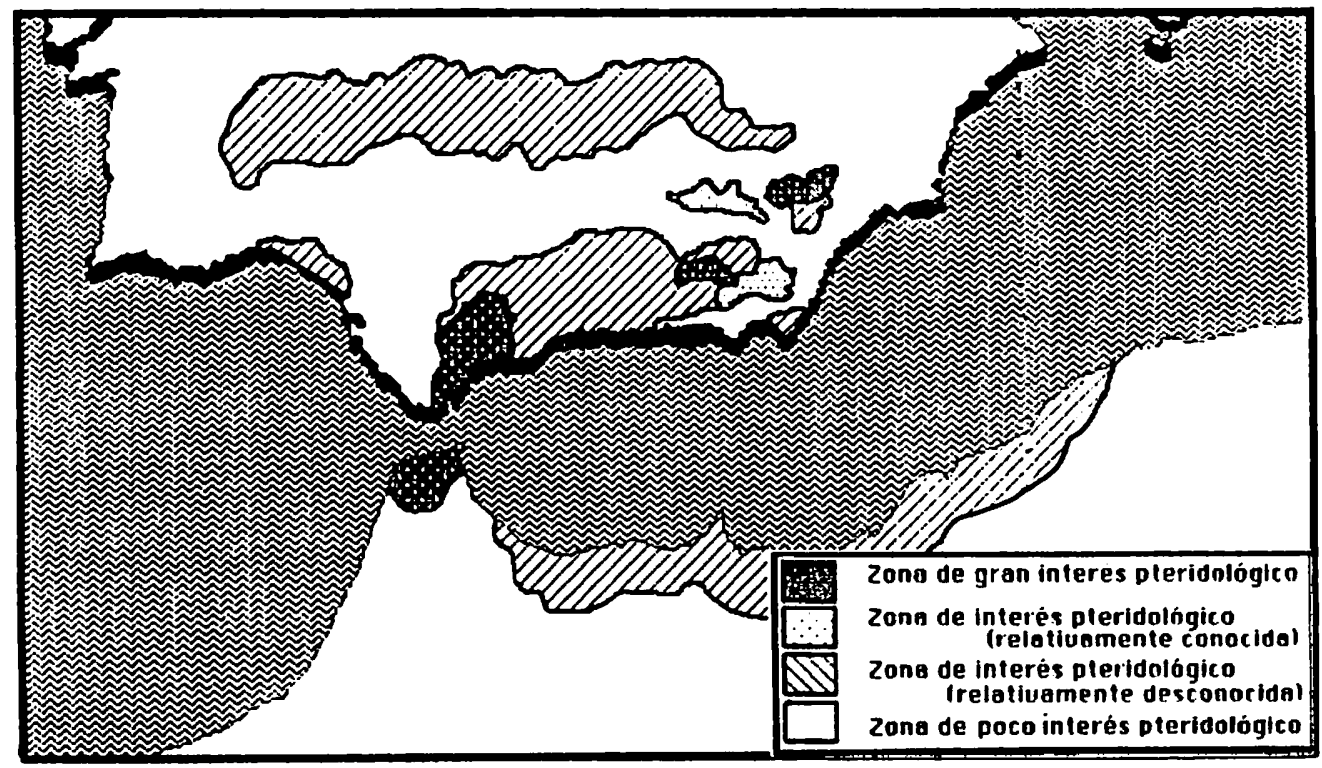

\section{LAMINA 5}

Mapa en el que se señalan algunas zonas suribéricas y norteafricanas atendiendo al nivel de conocimientos e interés pteridológicos que se poseen hasta el momento.

(Ampliado y modificado de SALVO, 1982). 
La encrucijada mediterránea goza así de una riquísima composición florística integrada por elementos procedentes de diversas latitudes más o menos alejadas de lo propiamente mediterráneo.

Factores espaciales y temporales, geográficos y cronológicos convergen en la definición mediterránea de nuestra flora pteridofítica.

Por localizar más este tratamiento especulativo acerca de la biología geográficoevolutiva de los helechos mediterráneos, centremos en el Sur ibérico y en su correspondiente complemento norteafricano, el marco de nuestras reflexiones. Precisamente aquí, la variabilidad de sustratos litológicos y edáficos o la amplia gama de meso y microclimas, conceden al paisaje la adquisición de plurales expresiones entre las que destacan per se unos singulares albergues ecosistemáticos relegados en lugares generalmente escondidos y de difícil acceso, donde se permite la vida en equilibrio con el medio, de unas especies vegetales pteridofiticas que requieren de condiciones ecológicas muy definidas para su desarrollo y que encuentran precisamente en estos parajes y no en otros.

Cuando se habla en términos generales de tlora endémica mediterránea, hay que nombrar de forma obligada a las tierras de Andalucía y del Norte de Marruecos, siendo muy elevado el número de endemismos que viven allí, teniendo especial interés aquéllos béticos-rifeños o ibero-mauritanos. Esta riqueza florística endémica, que por definición es una flora que sólo vive en estas latitudes, tiene un origen diverso como apuntábamos anteriormente al tratar la idea de encrucijada mediterránea; no obstante los procesos de especiación involucrados en la flora de estos lugares han sido indudablemente algunos de los factores más participativos en el origen de dicha riqueza florística.

Todo este tema es generalizable a la flora vascular, pero para los helechos deben tenerse en cuenta algunas matizaciones.

¿Dónde comienza y acaba el carácter endémico o el carácter relíctico entre las especies pteridofíticas?

En tiempos pretéritos los helechos ocuparon grandes extensiones sobre el planeta a lo largo de prolongados períodos que fueron completando su ya muy antigua historia evolutiva. Los reiterados acontecimientos geológicos y climáticos acaecidos en la Tierra y que tuvieron su manifestación en amplísimas regiones, influyeron decisivamente en la repartición geográfica de los helechos, que a priori ocupaban grandes áreas durante los períodos históricos de mayor esplendor de la flora pteridofítica sobre la Tierra. Esta decisiva influencia sería por ende negativa al quedar restringidos aquellos grandes areales según el arbitrio de los eventos ocurridos. Las especies habrían entonces de mantenerse en sólo algunos puntos muy determinados de todo el areal general que ocuparon antes; permaneciendo en dichos lugares como especies relícticas en áreas restringidas, donde las condiciones ecológicas más apropiadas para la vida de dichas especies permanecieron semejantes a las originales, tras lo acontecido con los eventos geológicos y climatológicos en nuestro planeta.

El carácter endémico (distribución restringida en un área concreta y delimitada de las especies) se deja ver con mayor dificultad en los helechos. Con la patente y proporcional prevalencia en los helechos de la isosporía y la endogamia, frente a la heterosporía y la fecundación cruzada, cabe acudir casi con exclusividad a los procesos 
microevolutivos para acercarnos a la dinámica de la especiación de pteridófitos.

La poliploidía se sitúa a la cabeza de los citados procesos microevolutivos, pudiendo entenderse ésta como una posible vía hacia la endemización, dado que los poliploides gozan de una "cantidad" superior de información genética que puede traducirse como una mayor eficacia ecológica y colonizadora, con capacidad incluso de relegar a los propios progenitores, de manera que en esta fase expansiva tales táxones serían ciertamente endémicos para el área donde tuvieron su origen.

En general suele hablarse de paleoendemismos, endemismos relícticos o paleopoliploides, manteniendo esa cómoda ambigüedad entre lo relíctico y lo endémico.

En todo caso, lo netamente trascendente es que los pteridófitos relícticos-endémicos son elementos con una aparición cada vez más infrecuente, poco conocidos - en no escasas ocasiones con serias dudas acerca de su taxonomía - y con el peligro de la extinción presionando sobre las poblaciones que aún viven en la actualidad.

\section{Biogeografía pteridofitica mediterránea}

La biogeografía o corología es una ciencia botánica que estudia la distribución de las plantas en la superficie terrestre y permite definir determinados territorios que quedan caracterizados por unos elementos florísticos que viven en los mismos.

En este contexto general, los helechos cobran especial importancia por su valor en las indagaciones epiontológicas, y biogeográficas en definitiva.

La estimación de los pteridófitos en la resolución de problemas epiontológicos está basada principalmente en la antigüedad del grupo y en otros factores como los relacionados con su propia capacidad de dispersión, limitada ésta a un vector físico (viento y/o agua) que conducirá a la mayoría de las esporas producidas por una planta determinada con una cierta agrupación y vecindad, excluyéndose a los animales en esa dispersión.

En los últimos tiempos se han desarrollado un conjunto de metodologías para el conocimiento pteridogeográfico de algunas regiones del planeta, cuyo fundamento de trabajo está inspirado en el tratamiento numérico de la información que se maneja. Para la región mediterránea habría que destacar los trabajos de PICHI - SERMOLLI (1979), JERMY (1984) o SALVO, este último autor con una prolífica labor de investigaciones pteridogeográficas, entre otras, centradas básicamente en el Sur ibérico y el Norte de Africa, con amplitud hacia los archipiélagos macaronésicos, realizadas a lo largo de los años 80 en colaboración con diversos investigadores (DIEZ \& SALVO, 1981; VARO \& SALVO, 1982; SALVO, 1982; SALVO \& CABEZUDO, 1984; NIETO, CABEZUDO \& SALVO, 1987; SALVO \& ESCAMEZ, 1988; ESCAMEZ \& SALVO, 1988; PICHI - SERMOLLI, ESPAÑA \& SALVO, 1988; ROSELLO \& SALVO, 1988; SALVO, NIETO \& CABEZUDO, 1989; CASTILLO \& SALVO, 1989).

Considerando a las especies pteridofíticas que viven en la región mediterránea en la actualidad, PICHI - SERMOLLI (1979) estableció una agrupación de los helechos en distintos tipos biogeográficos separando cronológicamente aquéllos que viven en la región mediterránea desde antes o durante el Terciario, de aquéllos otros que viven aquí 


\begin{tabular}{|c|c|c|c|c|c|c|c|c|c|c|c|c|c|c|}
\hline & & GOA & RIF & IIM & AG & BAL & AL & CA & CO & GR & II & $J$ & Ma & $\mathbf{S E}$ \\
\hline \multicolumn{15}{|c|}{ Seleqinellacese } \\
\hline & Soleninollo denilculate & 1 & 1 & 1 & 1 & 1 & 1 & 1 & 1 & 1 & 1 & 1 & 1 & 1 \\
\hline & Soleninello bolenseo & 0 & 1 & 0 & 0 & Q & 0 & 0 & 0 & 0 & $\overline{0}$ & 0 & $\overline{0}$ & 0 \\
\hline \multicolumn{15}{|c|}{ Iooelacene } \\
\hline & 1000100 oolocoum & 0 & 0 & 0 & 1 & $T$ & 0 & 0 & 1 & 0 & 1 & $\overline{0}$ & 0 & 0 \\
\hline & Isoelos histrix & 0 & 1 & 1 & 1 & 1 & 0 & 1 & 1 & 0 & 1 & 1 & 0 & 0 \\
\hline & Isooles vololum volotum & $\overline{0}$ & 1 & 0 & 1 & 1 & 0 & 1 & 1 & 1 & 1 & 0 & $\overline{0}$ & 1 \\
\hline & Ieooles durioul & 0 & 0 & 0 & 1 & 1 & $\bar{D}$ & 1 & 0 & 0 & $i$ & 0 & $\overline{0}$ & 0 \\
\hline \multicolumn{15}{|c|}{ Equísetacesed } \\
\hline & Equisotum romosisalmum & 1 & 1 & 1 & 1 & 1 & 1 & 1 & 1 & 1 & 1 & 1 & 1 & 1 \\
\hline & Equígotum lolmololo & 0 & 1 & 1 & 1 & 1 & 1 & 1 & 1 & 1 & 1 & $\mathrm{~T}$ & T & 1 \\
\hline & Equisotum orvonso & 0 & 0 & 0 & 0 & 1 & 0 & D & 1 & $I$ & 0 & 1 & 0 & 1 \\
\hline & Equisotum pal ustro & 0 & 0 & 0 & $\overline{0}$ & 0 & 0 & 0 & 0 & 0 & $\overline{0}$ & $i$ & 0 & $\overline{0}$ \\
\hline \multicolumn{15}{|c|}{ Poliolocoso } \\
\hline & Pollotum nudum & 0 & 0 & 0 & $\overline{0}$ & D & $\overline{0}$ & 1 & $\overline{0}$ & $\overline{0}$ & 0 & 0 & 0 & $\overline{\mathbf{D}}$ \\
\hline \multicolumn{15}{|l|}{ Bolruchlocoso } \\
\hline & Bolruehium lunario & 0 & 1 & 0 & 0 & $\mathbf{0}$ & 1 & $\mathbf{0}$ & $\overline{0}$ & 1 & 0 & 0 & 1 & $\overline{0}$ \\
\hline \multicolumn{15}{|l|}{ Ophloqlossaceso } \\
\hline & Ophioglossum lusitenicum & $\mathbf{0}$ & 0 & 1 & 1 & 1 & 1 & 1 & 1 & 1 & 1 & 1 & $T$ & 1 \\
\hline & Oghioglossum vulogtum & 0 & 1 & 0 & $\underline{0}$ & 0 & 0 & 0 & 0 & 1 & 1 & 0 & D & $\overline{0}$ \\
\hline \multicolumn{15}{|c|}{ Oamendeceae } \\
\hline & Oamundo ronalls & 1 & 1 & 1 & 1 & 1 & D & 1 & 0 & $\overline{0}$ & 1 & 0 & 1 & $\mathbf{0}$ \\
\hline \multicolumn{15}{|c|}{\begin{tabular}{l|l} 
Polupadiacose \\
\end{tabular}} \\
\hline & Polypodium comoricum & $I$ & 1 & 1 & 1 & 1 & 1 & 1 & $T$ & 1 & 1 & 1 & 1 & $T$ \\
\hline & Polupodi um Intorjectum & $\mathbf{0}$ & 0 & 0 & 1 & $\mathbf{0}$ & $\overline{0}$ & 1 & 0 & O & 0 & 1 & 1 & 0 \\
\hline & Polupod um veloaro & 0 & 0 & 0 & 0 & Q & 1 & 0 & 0 & 1 & 0 & 0 & 0 & 0 \\
\hline \multicolumn{15}{|c|}{ Sinopteridocesel } \\
\hline & Chollenthos gugnchice. & 0 & 0 & 0 & 1 & $\overline{0}$ & 1 & 1 & 1 & 1 & 1 & 1 & $\overline{0}$ & $T$ \\
\hline & Chollenthos acrosfles & 0 & 1 & 1 & 0 & 0 & 1 & 1 & 1 & 1 & 1 & 1 & 1 & 1 \\
\hline & Choilenthos modoronolo & 1 & 1 & $\overline{0}$ & 1 & 0 & $T$ & $T$ & 1 & $I$ & 1 & 1 & 1 & I \\
\hline & Crotlonthes lingol & 0 & 0 & 0 & 0 & 1 & $\overline{0}$ & 0 & 1 & $\begin{array}{c}\mathbf{0} \\
\end{array}$ & 1 & 1 & 0 & $I$ \\
\hline & Cholienthos hisponice & 0 & 1 & 0 & 0 & 1 & 0 & 0 & 1 & 0 & 1 & 1 & 1 & $I$ \\
\hline & Nolholeone maranteo & 0 & 0 & $\bar{Q}$ & 0 & O & 0 & D & 0 & D & 1 & 0 & 1 & $\overline{0}$ \\
\hline \multicolumn{15}{|l|}{ Crupterranmacese } \\
\hline & Cruplogramme erispes & 0 & 0 & 1 & 0 & $\mathbf{0}$ & $\mathbf{0}$ & $\overline{0}$ & 0 & $i$ & 0 & 0 & $\overline{0}$ & $\mathbf{0}$ \\
\hline \multicolumn{15}{|c|}{ Plorideceed } \\
\hline & Ploris Incomplote & 0 & 0 & 1 & 0 & $\overline{0}$ & $\overline{0}$ & 1 & 0 & 0 & 0 & 0 & 0 & $\overline{0}$ \\
\hline & Pioris viltoto & 0 & 0 & 0 & 0 & 0 & 1 & 1 & 1 & 1 & 0 & 0 & 1 & 1 \\
\hline \multicolumn{15}{|c|}{ Adlentecese } \\
\hline & Adisatum copllius-voneris & 1 & $I$ & 1 & 1 & $T$ & 1 & 1 & 1 & I & $T$ & 1 & 1 & 1 \\
\hline \multicolumn{15}{|l|}{ Hemlonllidacese } \\
\hline & Anogromme loplophullo & 1 & $I$ & 1 & 1 & 1 & 1 & 1 & 1 & 1 & 1 & 1 & 1 & 1 \\
\hline & Cosentinio volleo & 1 & 1 & 1 & 1 & 1 & 1 & 1 & 1 & 1 & 1 & 1 & 1 & 1 \\
\hline acoeos & & & & & & & & & & & & & & \\
\hline & Merslles boterdas & 0 & 0 & 0 & 0 & 1 & 0 & 0 & 1 & 0 & 0 & 0 & $\overline{0}$ & 0 \\
\hline & Mersiles otrigoso & 0 & 0 & 0 & 0 & 0 & 1 & D & 0 & 0 & 0 & 0 & 0 & 0 \\
\hline & Pliulerio globulitero & 0 & 0 & 0 & 0 & 1 & 0 & 0 & $\mathbf{0}$ & 0 & 0 & 0 & 0 & 0 \\
\hline & Pilulario minute & 0 & 0 & 0 & 1 & 0 & 0 & D & 0 & 0 & 0 & 0 & 0 & 0 \\
\hline Hymesophrllacese & & & & & & & & & & & & & & \\
\hline & Yendonboschlo speclose & 0 & 0 & 0 & 0 & $\overline{0}$ & 0 & 1 & 0 & 0 & 0 & 0 & 0 & 0 \\
\hline Culcitacead & & & & & & & & & & & & & & \\
\hline & Culcito macrocerpa & D & 0 & 0 & 0 & 0 & 0 & $T$ & 0 & 0 & 0 & 0 & $\overline{0}$ & 0 \\
\hline Hypolopidacenel & & & & & & & & & & & & & & \\
\hline & Pteridium oquilinum & 1 & 1 & 1 & 1 & 1 & 0 & 1 & 1 & 1 & 1 & 1 & 1 & 1 \\
\hline Thelyptertdacose & & & & & & & & & & & & & & \\
\hline & Thalyptorlo polustris & 0 & $\mathbf{0}$ & $\mathbf{0}$ & 0 & 1 & 0 & 1 & $\mathbf{0}$ & 0 & 1 & 0 & 0 & 0 \\
\hline & Chriatolio dontato & 0 & 0 & 1 & $\overline{0}$ & Q & 0 & 1 & 0 & 0 & 0 & 0 & 0 & 0 \\
\hline
\end{tabular}




\begin{tabular}{|c|c|c|c|c|c|c|c|c|c|c|c|c|c|c|}
\hline & & GUR & RIf & IIN & AG & $\mathbf{B A L}$ & AL & $\mathbf{C A}$ & CO & GR & II & $J$ & $\mathrm{MA}$ & SE \\
\hline Asplentecose & & & & & & & & & & & & & & \\
\hline & Asplonium hemionitis & $T$ & 0 & 1 & 0 & 0 & $\overline{0}$ & $\overline{0}$ & $\overline{0}$ & 0 & 0 & 0 & 0 & 0 \\
\hline & Asplenlum mertnum. & 1 & 0 & 1 & 1 & 1 & 0 & 1 & 0 & 0 & 0 & 0 & 0 & 0 \\
\hline & A. pelrorchoe polrerchoo & 0 & 0 & 0 & 1 & 0 & 1 & 1 & 1 & 1 & 1 & 1 & 1 & 1 \\
\hline & A. potrerchoo blvalong & 0 & 0 & 0 & 0 & 0 & 0 & 1 & 0 & 0 & 0 & 0 & $\overline{0}$ & 1 \\
\hline & A. Irichomenes quedrivelens & 1 & 1 & $T$ & 1 & 1 & 1 & 1 & 1 & 1 & 1 & 1 & 1 & $T$ \\
\hline & A trichomenos pochyrechis & 0 & 0 & 0 & $\overline{0}$ & 0 & 0 & $\overline{0}$ & 0 & 1 & 0 & 1 & 1 & 0 \\
\hline & Asplontum virido & 0 & 0 & 0 & 0 & 0 & 0 & D & 0 & 1 & 0 & 0 & 0 & 0 \\
\hline & Asplontum fontonum & D & 0 & 0 & 0 & 0 & 0 & $\overline{0}$ & 1 & 1 & 0 & 1 & 0 & 0 \\
\hline & Asplonium forozionse & 0 & 0 & 0 & 0 & 0 & 1 & 0 & Q & 1 & 0 & 0 & 0 & 0 \\
\hline & Asplenium olliotil & 1 & 1 & $T$ & $i$ & 1 & 1 & 1 & 1 & 0 & 1 & 1 & $T$ & 1 \\
\hline & Asplonium onopierls & 1 & 0 & 1 & 1 & 1 & 1 & 1 & 1 & 1 & 1 & 1 & $T$ & 1 \\
\hline & Asplenium edientum - nigrum & 0 & 1 & $T$ & 1 & 0 & $T$ & $T$ & 0 & 1 & 0 & 0 & $\overline{0}$ & 0 \\
\hline & Asplonium splonlrionalo & 0 & $\overline{0}$ & 0 & D & $\overline{0}$ & 1 & $\overline{0}$ & $\overline{0}$ & 1 & 0 & 0 & 1 & $\overline{0}$ \\
\hline & Asplonium seolosil & 0 & 0 & 0 & D & 0 & 0 & 0 & 0 & 0 & 0 & $T$ & $\overline{0}$ & 0 \\
\hline & Asplonium ruto-murerio & 0 & 0 & 1 & 0 & 0 & 1 & 0 & 1 & $T$ & 0 & $T$ & $T$ & 1 \\
\hline & Asplontum scolopendrium & 0 & 1 & $T$ & 0 & $\overline{0}$ & 1 & 1 & $T$ & $T$ & $T$ & 1 & $i$ & 1 \\
\hline & osgltiolum & 0 & 1 & 1 & 0 & $\mathbf{0}$ & 0 & 1 & $\overline{0}$ & $\overline{0}$ & 0 & 0 & 0 & 0 \\
\hline & Asplonium cotorech & 1 & 1 & 1 & 1 & 0 & $T$ & $T$ & $T$ & 1 & 1 & 1 & $T$ & 1 \\
\hline & bolondulosum & 0 & 1 & 0 & 0 & 0 & 0 & 1 & 1 & $T$ & 0 & 1 & 1 & 1 \\
\hline \multicolumn{15}{|c|}{ Athyriocese } \\
\hline & Cystopleris freqlils freplils & 0 & 1 & 0 & $\bar{D}$ & 0 & 1 & 1 & $i$ & $T$ & 1 & $T$ & $T$ & 1 \\
\hline & Cysloploris rreglito nuteri & 0 & 0 & 0 & 0 & 0 & 0 & 0 & 0 & 1 & 0 & 1 & 0 & 0 \\
\hline & Cygtogioris dickiegno & 0 & 0 & 0 & 0 & 0 & 1 & 1 & 0 & 1 & 1 & 1 & 1 & 0 \\
\hline & Cystoptoris viridulo & 0 & 0 & 0 & 1 & 0 & 0 & $\overline{0}$ & 0 & 1 & 1 & 0 & 0 & 0 \\
\hline & Althyrlum filix-fomino & 0 & 1 & 1 & 1 & 0 & 1 & $T$ & 0 & 1 & 1 & 0 & 1 & 0 \\
\hline & Diplaz & 0 & 0 & 0 & $\overline{0}$ & 0 & 0 & $T$ & 0 & 0 & 0 & 0 & 0 & 0 \\
\hline \multicolumn{15}{|c|}{ Asploleceoe } \\
\hline & Dryopteris fillx-mas & 0 & 1 & $\overline{0}$ & 0 & 0 & 1 & $i$ & 1 & $T$ & 0 & $T$ & 1 & 0 \\
\hline & Oruopteris offinie ofínis & 0 & 0 & 0 & $\overline{0}$ & 0 & 0 & 0 & 0 & 1 & 1 & 0 & 0 & 0 \\
\hline & Oryoptoris offinls borrert & 0 & 0 & 0 & 0 & 0 & $\mathbf{0}$ & 0 & 0 & $i$ & 0 & 0 & 0 & 0 \\
\hline & Oryopteris lyrrhono. & 0 & 0 & 0 & 0 & 0 & $\overline{0}$ & $\overline{0}$ & 0 & 1 & 0 & 0 & 0 & 0 \\
\hline & Oryopleris submentene & 0 & 0 & 0 & 0 & 0 & 0 & 0 & 0 & 1 & 0 & 1 & 1 & 0 \\
\hline & Drsopioris quencilco. & 0 & 0 & 0 & 0 & 0 & $\overline{0}$ & 1 & $\bar{D}$ & 0 & 0 & 0 & 0 & 0 \\
\hline & Polystichum lonchitis & 0 & 0 & 0 & 0 & 0 & 1 & 0 & $\overline{0}$ & 1 & 0 & $T$ & 0 & 0 \\
\hline & Pol yslichum sotiforum. & 0 & 1 & $\overline{0}$ & 0 & 0 & 0 & 1 & $\overline{0}$ & 0 & 1 & $T$ & 1 & 0 \\
\hline & Pol uslichum oculootum & 0 & D & 0 & 0 & 0 & $T$ & 1 & 0 & 1 & 0 & $T$ & 1 & 0 \\
\hline Doval & & & & & & & & & & & & & & \\
\hline & Devallio caneriansis & 1 & D & $T$ & $\overline{0}$ & $\overline{0}$ & 0 & 1 & D & 0 & 0 & 0 & 0 & 0 \\
\hline Blechnaceed & & & & & & & & & & & & & & \\
\hline & Blochnum aplcent & 0 & 0 & 1 & 1 & 0 & D & 1 & 0 & Q & 1 & 0 & 0 & 0 \\
\hline & & & & & & & & & & & & & & \\
\hline & SUMA & 16 & 28 & $2 \theta$ & 28 & 24 & 31 & 45 & 31 & 44 & 35 & 37 & 34 & 27 \\
\hline
\end{tabular}

\section{LAMINA 6}

Tabla en la que se expresa la presencia (1) o ausencia (0) de las especies de pteridófitos, agrupadas por familias, para las localidades que se indican:

MARRUECOS: GUR, Macizo del Gurugú; RIF; TIN, Península Tingitana.

PORTUGAL: AG, Algarve; BAL, Baixo Alentejo.

ESPAÑA: AL, Almería; CA, Cádiz; CO, Córdoba; GR, Granada; H, Huelva; J, Jaén; MA, Málaga y SE, Sevilla. 
desde el Cuaternario; tipología que fue posteriormente revisada y reordenada por PICHI-SERMOLLI, ESPAÑA \& SALVO (op. cit.), siendo los diferentes tipos:

Terciario: Heterocóricos, de amplia distribución por todo el mundo.

Circumboreales, distribuidos en el Hemisferio Norte.

Mediterráneos y de regiones orientales próximas.

Latemediterráneos (= mediterráneos y de regiones adyacentes).

Pantropicales, distribuidos en los trópicos y subtrópicos.

Relictos paleomediterráneos.

Semimediterráneos ( $=$ mediterráneos que penetran escasamente en regiones continuas).

Eumediterráneos.

Cuaternario: Heterocóricos, de amplia distribución en el mundo.

Circumboreales, distribuidos en el Hemisferio Norte.

Latemediterráneos (= mediterráneos y de regiones adyacentes).

En base a esta tipología panbiogeográfica —que recoge para cada tipo el carácter espacial y temporal- y con la participación de otros índices y análisis numéricos utilizados, se construye todo un procedimiento metodológico que permite evaluar comparativamente distintas Unidades Geográficas Operativas (OGUs) y extraer de dicho proceso comparativo unos resultados que dan pie a muy interesantes conclusiones tras su adecuada interpretación

Más adelante podremos comprobar la aplicación de este modelo metodológico a una pteridoflora concreta, la del Macizo del Gurugú.

\section{Los helechos del Macizo del Gurugú (NE Marruecos, provincia de Nador)}

\section{El Gurugú}

Prácticamente desde Melilla comienza a arrancar el macizo eruptivo del Gurugú, ubicado en la base de la península de Tres Forcas, en la parte central de la región de Guelaya, de la que es sin duda el enclave pteridofítico de mayor interés, formando parte de las estribaciones del Rif Oriental.

La cumbre del macizo está situada hacia el E, coronada por varios picos: Basbel $(789 \mathrm{~m})$, Kol-La $(737 \mathrm{~m})$, Tizi-Taquiras $(817 \mathrm{~m})$ y Gurugú $(893 \mathrm{~m})$, pico que da nombre al macizo y que está unido a Taquigriat $(880 \mathrm{~m})$. La proximidad a la costa oriental determina el aspecto de esta cara que aparece profundamente escarpada y surcada por angostos y pendientes barrancos, como el Barranco del Lobo (Jándak el Ussen) o el Barranco del Infiemo (Jándak el Zimessi), que junto a otros de menor relevancia desembocan en la Mar Chica.

La constitución geológica de todo el macizo es muy monótona y está determinada por su naturaleza volcánica. Predominan las rocas andesíticas, ocupando la mayor extensión y que corresponden a la erupción más antigua. También aparecen basaltos, 
dacitas y diabasas.

De este macizo surge un curso fluvial de relativa importancia: el río de Oro, que recoge las aguas de las vertientes septentrionales de la meseta de Tazuda y de las vertientes occidentales de los picos Gurugú y Taquigriat, existiendo varios cauces de menor importancia que llevan agua cuando las lluvias aparecen. Destacan además varios manantiales naturales como la fuente de Traras (en Igsar Izaruren) o la del Barranco del Lobo.

Atendiendo a sus características climáticas y a los datos aportados por la estación meteorológica más cercana (Melilla), el bioclima es típicamente termomediterráneo, con precipitaciones entre los 200 y $350 \mathrm{~mm}$ anuales, variando el ombroclima desde árido en las zonas basales hasta seco o incluso subhúmedo en algunos puntos de las cotas superiores y de exposición NE (véase diagrama ombrotérmico), debido fundamentalmente a la aparición frecuente de un cinturón nebuloso por encima de los 500 metros de altitud propiciado por los vientos de Levante y que está constituido por masas de aire húmedo que determinan una humedad relativa elevada.

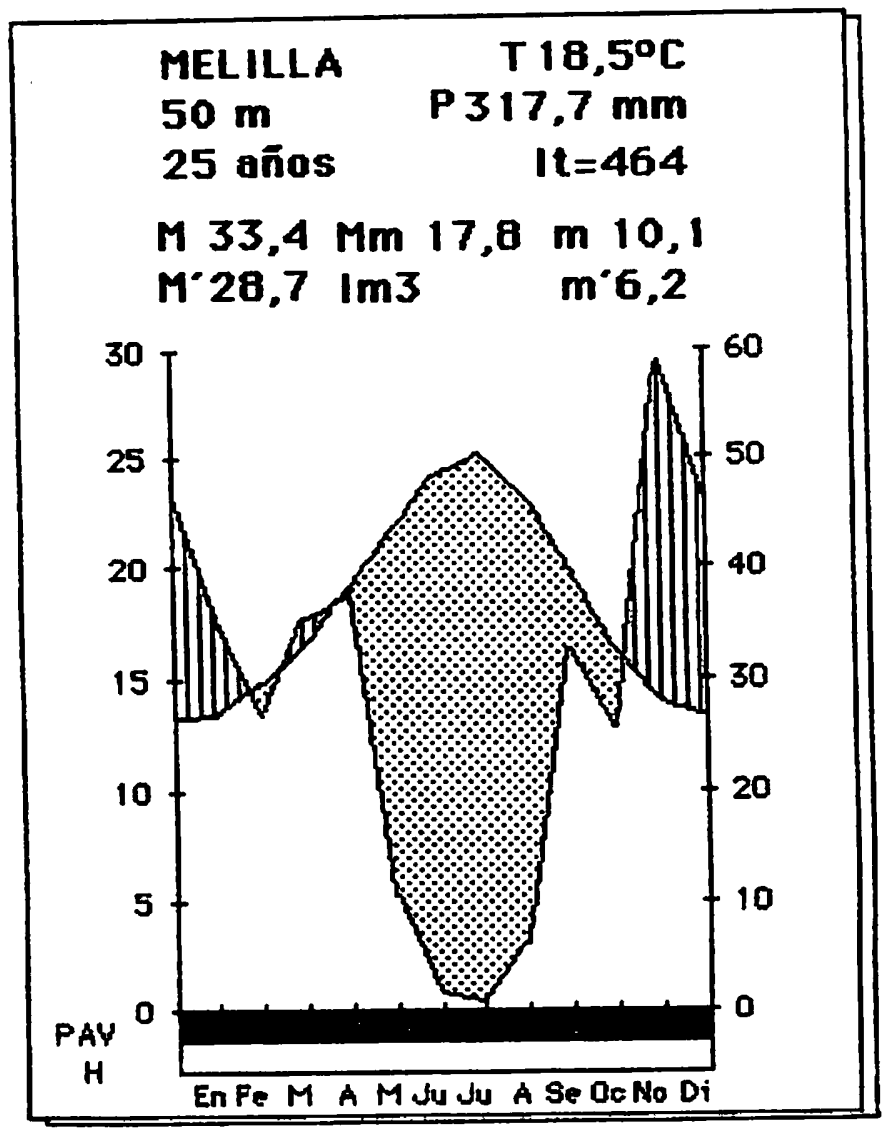

Diagrama Ombrotérmico elaborado en base a los datos de la estación meteorológica de Melilla (Tomado de ESCAMEZ y SALVO, 1988). 
MATORRALES ESPINOSOS

CADUCIFOLIDS TERMOMEDITERRANEOS

DE CARACTER ARIDO A SEMIARIDO

MATORRALES ESPINOSOS

PERENNIFOLIOS TERMOMEDITERRANEOS

DE CARACTER SEMIARIDO A SECO

VEGETACION FISURICOLA

满

VEGETACION DE RIBERAS DE RAMBLAS

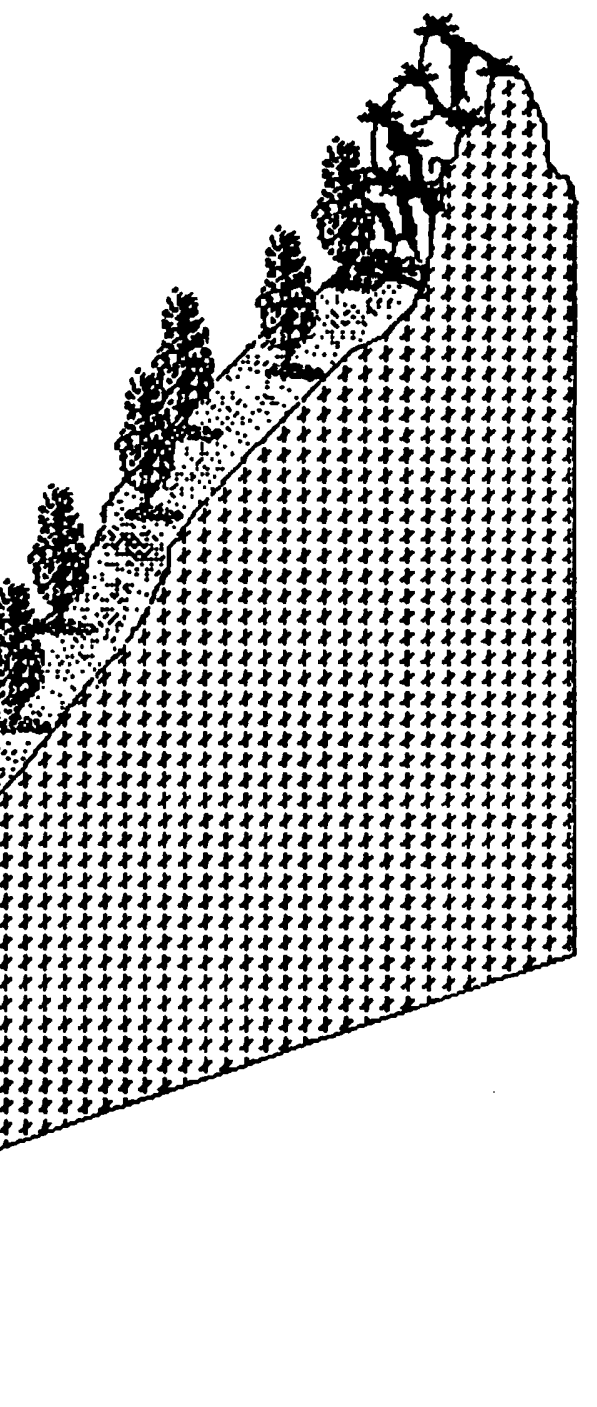

\section{LAMINA 7}

Disposición catenal de las comunidades vegetales naturales en el Macizo del Gurugú. 
En el macizo del Gurugú, los barrancos que lo surcan constituyen el albergue adecuado para los helechos que viven en esta zona, encontrando en ellos las condiciones mínimas, que no óptimas, para su desarrollo.

No obstante este enclave cobra un especial significado por diversas razones, entre otras por tratarse del único lugar en muchos kilómetros a la redonda donde puede encontrarse una flora pteridofítica, que presenta un marcado carácter atlántico, en contraste con los valores climáticos antes expuestos.

\section{Flora pteridofítica del Gurugú. Una ojeada histórica}

Durante la primera mitad de este siglo, la zona de Melilla incluyendo el que fue territorio anejo durante el Protectorado español de Marruecos, fue muy visitada por diversos botánicos fanerogamistas que dedicaron una especial atención a los helechos del macizo del Gurugú.

Los Hermanos de la Doctrina Cristiana SENNEN y MAURICIO, el primero por aquél entonces profesor del Colegio de la Bonanova de Barcelona y miembro honorario y laureado de la Sociedad Botánica de Francia, entre un amplio elenco de titulaciones, y el segundo, profesor en el Colegio de la Doctrina (La Salle-El Carmen) de Melilla, comenzaron en 1928 una labor de recolección e identificación de la flora de Melilla y su territorio. El trabajo lo inició el Hermano MAURICIO desde Melilla, dirigiéndolo el Hermano SENNEN desde Barcelona y resolviendo éste los problemas y dudas que iban surgiendo, hasta que en Junio de 1930 ambos iniciaron las "Campañas Botánicas" que se irían repitiendo en afios sucesivos (1930-1935). En 1934 publican el "Catálogo de la flora del Rif Oriental y principalmente de las cábilas lindantes con Melilla", en el que citan unos 2.000 táxones de flora vascular entre especies, subespecies, formas y variedades, con la personal concepción que el Hermano SENNEN otorgaba a la definición de especie vegetal; incluyendo las citas publicadas con anterioridad por los doctores CABALLERO, de la Universidad de Madrid; PAU, de Segorbe, FONT QUER, director del Museo de Ciencias Naturales de Barcelona, MAS y GUINDAL, Teniente Coronel e Inspector de Farmacia Militar, MAIRE, profesor de la Facultad de Ciencias de Argel y CANDEL, geólogo y catedrático de ciencias naturales en el Instituto de Melilla.

No procede aqui detallar la labor de estos ilustres botánicos en el área norteafricana, motivo más que suficiente y justificado para la realización de un ensayo profundo y de conjunto , pero se ha de distinguir el trabajo de SENNEN y MAURICIO por su vinculación directa a Melilla y a la localidad que nos ocupa: el macizo del Gurugú.

A partir de los datos recopilados por estos dos últimos autores a lo largo de sus ya mencionadas "Campañas Botánicas", SENNEN publica en 1936 "Campagnes botaniques du Maroc Oriental de 1930 d 1935 des fréres Sennen et Mauricio.

(2) Véase en esta misma publicación "Algo más de doscientos años de preocupación por la Naturaleza en Melilla y su tierra" de Antonio Gonźlez Bueno. 
EE.CC.", donde iría ordenando tales informaciones cronológica y topográficamentc, siguiendo para ello el esquema de las "Campañas" durante esos años.

Un párrafo que SENNEN eligió para abrir esta obra suya, podría servirnos perfectamente para guiar nuestro trabajo en relación con los helechos del Gurugú:

\author{
"Il faut toujours chercher \\ et ne jamais se lasser \\ L'exploration d' un seul massif \\ est une oeuvre de longue haleine, \\ qu'elle n'est jamais achevée".
}

De estas dos obras citadas ("Catálogo de la flora ..." y "Campagnes botaniques ...") hemos podido extraer un total de referencias pteridofíticas que ascienden al número de diecisiete especies (véase Lámina 6 y Lámina 8), si bien SENNEN y MAURICIO (op. cit.) recogen unos táxones cuya identidad desconocemos, dada su incorrecta nominación y al no poder estudiar los pliegos de herbario de dicho material; $v$. $g r$. Asplenium lusus-subtripinnatum Walter o Asplenium alleizettei Sennen.

A lo largo de las exploraciones realizadas por nosotros en el Gurugú, excluyendo la zona prohibida de Taquigriat-Gurugú, hemos podido detectar la presencia de los pteridófitos que aparecen en la tabla de la Lámina 8, considerando en dicho listado la existencia de Davallia canariensis (L.) Sm., Asplenium marinum L., Hippochacte ramosissima (Desf.) Bruhin y Equisetum telmateia Ehrh., habiendo depositado cl material recolectado en el Herbario del Departamento de Biología Vegetal de la Universidad de Málaga (MGC).

D. canariensis fue citada para el Gurugú por FONT QUER, botánico que habría de realizar una intensa labor investigadora en toda la zona del Protectorado español cn Marruecos, donde estuvo destinado para prestar sus servicios como famacéutico militar. De entre los numerosos trabajos de FONT QUER, "Sobre la flora de Melilla" (1916), nota de dos páginas publicada en el Boletín de la Real Sociedad Española de Historia Natural, nos sugiere un grato interés por versar sobre nuestro entorno más cercano y por las citas que incluye.

A pesar de no haberse hallado hasta el momento en nuestras recolecciones a $D$. canariensis, hemos tenido la oportunidad de estudiar los pliegos de esta especic despositados en el Herbario del Colegio La Salle-El Camen de Melilla (cuya ausencia de ficha no nos aportó ninguna información de valor) y en el Herbario del Institut Scientifique de Rabat, donde se encuentra un ejemplar recolectado en el Gurugú por cl propio FONT QUER en 1929.

En su "Excursión botánica a Melilla en 1915", CABALLERO (1917) recoge la cila de $A$. marinum para el macizo del Gurugú, aunque en los mencionados herbarios no hemos podido encontrar pliegos testigos, si bien su presencia, aunque dudosa en la actualidad, también fue aceptada por JAHANDIEZ \& MAIRE (1931), SENNEN \& MAURICIO (op. cit) y MAIRE (1952).

Por otro lado, los dos equisetos ("colas de caballo") que incluimos en la lista de cspecies pteridofíticas del Gurugú no han sido localizados por nosotros aunque presumimos su existencia bajo la obligada duda, después de las consultas bibliográficas y de herbario investigadas, éstas últimas en el ya nombrado Herbario del Colegio La 


\begin{tabular}{|c|c|c|c|c|c|c|c|c|c|c|c|}
\hline TICH PTERIDOLOBICA & 1 & 2 & 3 & 1 & 5 & ! & 7 & 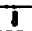 & I & 10 & ii \\
\hline Especios & Gurugé & Itanglitana & M. Algecires & Bormeta & Mijes & Nevado & Bata & $M$ & 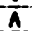 & $\overline{\mathbf{C}}$ & $\overline{1} \overline{p o} \overline{\mathrm{B}} \overline{\mathrm{O}}$ \\
\hline Adiantum cepillus vener is & 1 & 1 & 1 & 1 & 1 & i & i & 1 & 1 & 1 & HE I IER \\
\hline Anor ranmo leplophyllo & 1 & $i$ & 1 & $\frac{1}{1}$ & 1 & $i$ & i & 1 & 1 & $-\frac{1}{1}$ & HE I IER \\
\hline Asplenlem billotil & 1 & 1 & 1 & 1 & i & 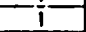 & 1 & $i$ & 1 & 1 & LAIEMED IER \\
\hline Asplentum celerech & 1 & 1 & 0 & 1 & 1 & 1 & 1 & 1 & 0 & 1 & MED Y ROP IER \\
\hline Asplenium hemionilis & 1 & $i$ & 0 & 0 & $\overline{0}$ & i & $\overline{0}$ & $\overline{0}$ & 1 & $\overline{0}$ & PAL EOMID IER \\
\hline Asplanlum mer tnum & 1 & 1 & 0 & $\overline{0}$ & $\overline{0}$ & $\overline{0}$ & $\bar{D}$ & 1 & $i$ & $\frac{1}{1}$ & LAIEMIDCUA \\
\hline Asplonium onoplerts & I & 1 & 1 & i & 1 & 1 & i & 1 & 1 & $i$ & SEMI IER \\
\hline Asplenium tr ichomenes & 1 & 1 & 1 & 1 & 1 & 1 & 0 & $i$ & $i$ & 1 & HEI IER \\
\hline Cheilenthes moder ensis & i & $\overline{0}$ & 0 & 0 & $i$ & $\frac{1}{1}$ & 0 & 1 & i & $\frac{1}{0}$ & SEMIMID IER \\
\hline Cosentinlo velles & $\mathrm{T}$ & $T$ & 0 & 0 & I & 1 & 1 & 1 & $i$ & 0 & MED Y ROP IER \\
\hline Dovallia coner lensis & 1 & i & 1 & 1 & $\overline{0}$ & 0 & $\overline{0}$ & 1 & 1 & 0 & PALOAEO IER \\
\hline Equisetum lelmatels & 1 & $\mathrm{~T}$ & $i$ & 0 & 0 & 1 & $\overline{0}$ & i & $i$ & 1 & CIRCUMB IIR \\
\hline Hippocheete remosvisime & i & 1 & $i$ & $\frac{\pi}{1}$ & 1 & $\frac{1}{1}$ & 0 & 1 & 1 & 0 & HE I IER \\
\hline Dsmunderesilis & 1 & 1 & 1 & 0 & 0 & 0 & 0 & 1 & $\frac{1}{1}$ & $i$ & IIE I IER \\
\hline Polypodium conbricum & 1 & 0 & 1 & 1 & i & 1 & i & 1 & 1 & $i$ & TAIEMTD IER \\
\hline Pler tótium oquilinum & 1 & I & 1 & 1 & $i$ & 1 & 0 & 1 & 0 & 1 & HEI IER \\
\hline Soleninello denitculato & $i$ & i & 1 & $i$ & 1 & $i$ & 1 & $i$ & $\frac{5}{1}$ & 1 & SEMI IER \\
\hline & 17 & 15 & 12 & 11 & 12 & 13 & 8 & & & & \\
\hline TOTMES & & 25 & 21 & 16 & 17 & 37 & 12 & & & & \\
\hline
\end{tabular}

\section{LAMINA 8}

Tabla donde se indica la presencia 1) o ausencia (0) de los pteridófitos que viven en el Macizo del Gurugú y en otras localidades - OGUs - comparadas: Península Tingitana, Macizo de Algeciras, Sierra Bermeja, Sierra de Mijas, Sierra Nevada y Cabo de Gata (columnas 1-7).

En las columnas 8,9 y 10, se expresa respectivamente la presencia (1), o ausencia (0), de dichas especies en la región Mediterránea (M), Macaronésica (A) o Eurosiberiana (C).

La columna 11 recoge los tipos biogeográficos en que se incluyen las especies citadas.

(Modificado y reducido de ESCAMEZ y SALVO, 1988). 
Salle-El Carmen de Melilla, donde desafortunadamente los pliegos carecían de fichas identificativas de los ejemplares, desconociendo con certeza su lugar de procedencia.

CABALLERO indicó la existencia de un Equisetum arvense L. para la zona de Melilla, como también aceptaron posteriormente SENNEN \& MAURICIO (op. cit.) (Beni-Sicar y Valle de las Adelfas), no obstante esta información quedó rebatida en la Flore de l'Afrique du Nord. Vol. I de MAIRE (op. cit.), donde textualmente se exponía:

"L'E. arvense L. a été indiqué par Milde. Fil. Eur., p. 217 comme rarissime dans l'Afrique du Nord. Cette indication doit reposer sur une confusion d'étiquetle, car l'E. arvense n'a jamais été trouvé de façon certaine dans l'Afrique du Nord, bien qu'il ait été indiqué plus récemment par CABALLERO d Melilla par confusion avec l'E. ramosissium".

Tanto en esta obra de MAIRE, como en el Catologue des plantes du Maroc. Vol.I de JAHANDIEZ \& MAIRE (op. cit.) se incluían la mayoría de las citas pteridofíticas dadas para el Gurugú.

La profusión de publicaciones botánicas en particular y biológicas y geológicas en general aparecidas a lo largo de la primera mitad de este siglo y centradas en la temática norteafricana y, por lo que nos atañe, más concretamente en el Protectorado, es un buen indicio para hacerse una idea del ambiente de gran actividad y motivación científica de aquellos tiempos y que estuvo ligado a los acontecimientos políticos y militares de la época. El Gurugú fue punto de encuentro de diversos naturalistas españoles vinculados al Ejército o bien a la investigación y la Universidad o a la enseñanza en general.

Sucintamente relacionaremos un breve elenco de los trabajos que aparecieron en aquellos años - además de los ya citados-y en los que se trató el estudio científico de la Naturaleza del Gurugú y sus alrededores.

El Dr. farmacéutico PAU, en 1911 con "Una visita botánica al Rif”, da a conocer unas 100 especies vegetales recolectadas en Zeluán y Nador, hasta muy cerca del Gurugú. Más tarde en 1918, volvería a relacionar 100 especies recogidas en Tifasor por el que fue jardinero de los viveros de Río Martín, A. Aterido, en un artículo de 10 páginas titulado "Plantas de Melilla".

Nador, Zaio, Beni-Sicar, Gurugú, Uixan, Beni-Bu-Ifrur, Melilla, Zeluán, ... serían las localidades que fue recorriendo en sus recolecciones botánicas $C$. Vicioso durante el mes de Septiembre de 1921, realizando PAU en ese mismo año un artículo en el que se citaban unas 100 especies recolectadas en esas excursiones: "Una centuria de plantas del Rif Oriental".

En 1912 CABALLERO, entonces profesor del Jardín Botánico de Madrid, había iniciado un proyecto de investigación botánica en el Rif: "Enumeración de las plantas herborizadas en el Rif en 1912" que estuvo dirigido por O. de BUEN y que veria la luz en 1915. El proyecto contenía una labor de recolección e identificación botánica por diversos itinerarios que pasarían por Nador, Gurugú, Cabo de Agua, ... con la enumeración ordenada de las especies (395 especies más 10 especies o variedades nuevas), citando sus localidades y completando el trabajo con descripciones de los táxones y otras notas de interés. 
El prolífico farmacéutico militar MAS Y GUINDAL, quien publicó gran cantidad de trabajos botánicos y en menor medida mineralógicos, de índole muy diversa, tocando múltiples aspectos que irían desde lo estrictamente florístico o taxonómico a lo relativo a la farmacología marroquí, durante 1929 y 1930 visitó Melilla y su zona, dando fe de sus siempre bien aprovechados viajes -en lo científico- los artículos aparecidos en el Telegrama del Rif, que en los días 8, 9 y10 de agosto de 1929 se titularon "Impresiones de unos viajes por Melilla: Notas rápidas de minería, botánica y famacologia".

En abril de 1930 aparece, en la revista Mauritania "Mis excursiones botánicas por la zona de Melilla. Notas rápidas de un viaje"; posteriormente y durante los meses de julio, agosto y septiembre de ese mismo año, MAS Y GUINDAL relataría nuevamente sus "Impresiones de un viaje por la zona de Melilla. Notas rápidas de mineralogía, botánica y farmacognosia".

En "La misión Bolivar en Marruecos y nuestras recolecciones de plantas", MAS Y GUINDAL publica en 1931 los resultados de las recolecciones botánicas llevadas a cabo cuando el Alto Mando de Marruecos hubiera de designarle, como Jefe de los Servicios Farmacéuticos Militares del Protectorado, para acompañar a la misión científica dirigida por el Dr. C. BOLIVAR, celebrada durante el 11 al 30 de junio de 1930, recorriéndose entre otros lugares, las localidades de Tetuán, Zoco el Arbaa, Ben Karrich, Xauen, Bab-Taza, Monte Magat, Bensada, Ankot, Aci de Ketama, Telata de Ketama, Tainsa, Bab-Tizi, Igomar, Capamento Mola, Tisitaka, Imasines, Tarquist, Iguermalen, Tizi-Ifri, Teninde, Beni Amar, Torres de Alcalá, Ait-Tief, Jemis de Beni Bufrac, Had de Ruadi, Villa Sanjurjo, Axdir, Einsoven, Nekor, Melilla, Mar Chica, Gurugú ... BOLIVAR, catedrático de zoología de la Universidad Central de Madrid, llegó a Marruecos acompañado de catedráticos, profesores auxiliares, alumnos y un colector del Jardín Botánico, concibiendo una campaña naturalística íntegra que encontró en MAS Y GUINDAL el promotor de los estudios botánicos.

Por último, citar la labor docente e investigadora del geólogo, catedrático de ciencias naturales en el instituto de Melilla, R. CANDEL, quien era amigo de realizar salidas al campo con sus alumnos, habiendo publicado en 1931 "Excursiones por Marruecos. Macizo del Gurugú", en la revista Africa.

\section{Flora pteridofitica del Gurugú: Análisis pteridogeográfico}

Tras los recorridos botánicos que realizamos por el Gurugú, comenzamos a elaborar un análisis biogeográfico comparativo utilizando como elementos de comparación los helechos que viven en el Gurugú, y en otras localidades o Unidades Geográficas Operativas (OGUs) del Sur ibérico y Norte de Marruecos elegidas para dicha comparación (ESCAMEZ \& SALVO, op. cit.). Para este análisis se intentó adecuar la metodología biogeográfica numérica que había sido desarrollada con anterioridad para la zona mediterránea.

Los OGUs utilizados en el análisis comparativo fueron: el propio Macizo del Gurugú, la Península Tingitana, el Macizo de Algeciras, Sierra Bermeja, Sierra de Mijas, Sierra Nevada y Cabo de Gata.

Tras la aplicación de diversos indices, se determinaron algunas interesantes con- 

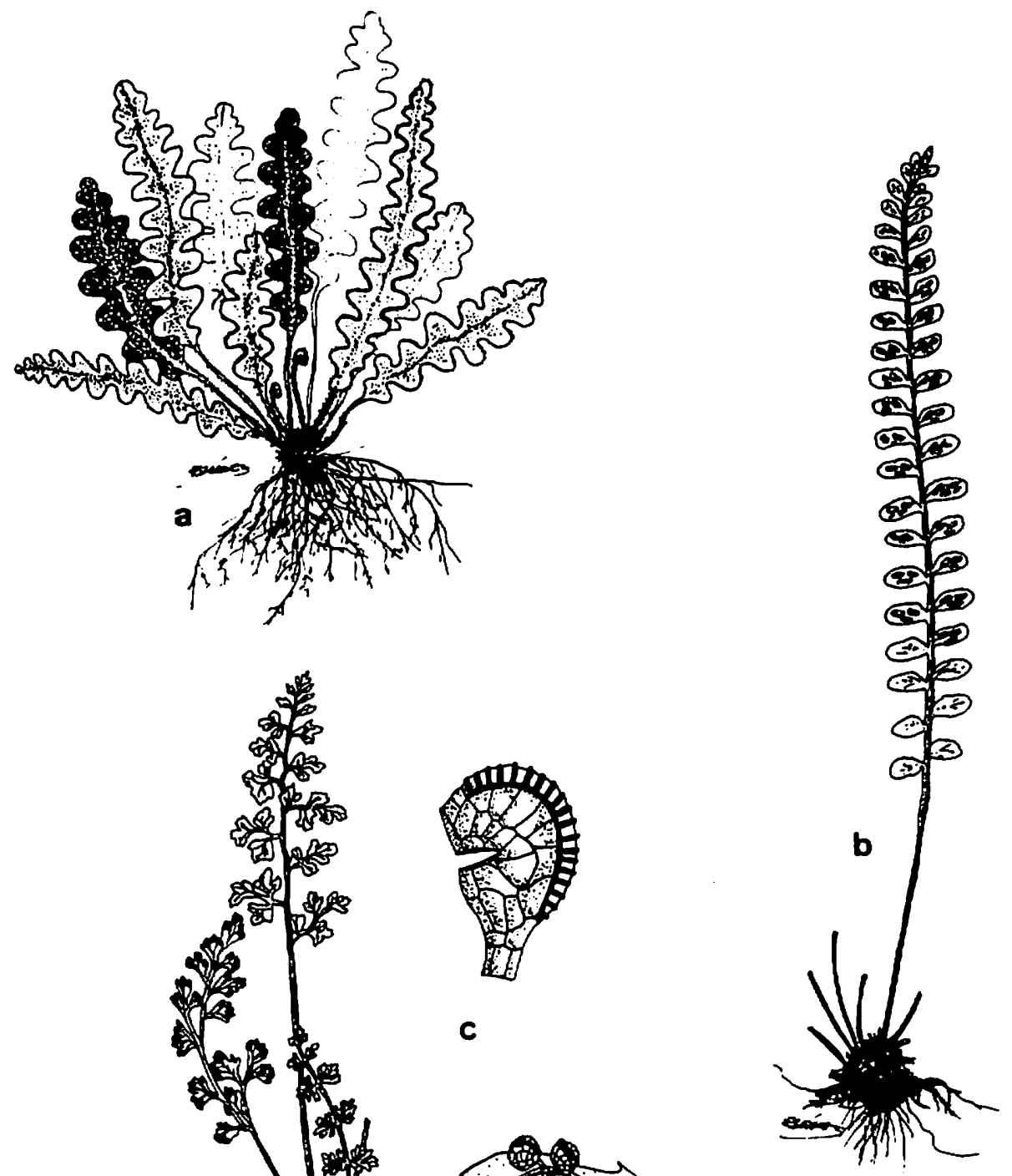

\section{LAMINA 9}

Helechos del Gurugú.

a, Asplenium ceterach L.; b, Asplenium trichomanes L.; c, Anogramma leptophylla (L.) Link, mostrando el detalle del margen de una fronde fértil con los esporangios y el aspecto de un esporangio. 
clusiones que podrían permitirnos al menos, intuir cómo debió ser la génesis de la flora pteridofítica que vive en nuestros alrededores.

Queda claro que el macizo del Gurugú constituye el enclave pteridofítico más interesante en toda la región de Guelaya, donde diversas especies de helechos encuentran allí un cobijo adecuado para completar sus ciclos de vida, gracias a la relativa altura del macizo que permite la permanencia del conocido cinturón nebuloso, dando lugar a unos altos niveles de humedad ambiental que se ve aún incrementada en las zonas de los barrancos, y gracias también a sus características orográficas, geomorfológicas y edáficas. Además el carácter antiguo de su peteridoflora, otorga al Gurugú la condición de refugio de táxones terciarios $(94,11 \%)$, porcentaje mayor al obtenido para la totalidad de la región mediterránea $(70,87 \%)$, viviendo en este macizo algunos relictos paleomediterráneos (Asplenium hemionitis L. y Davallia canariensis (L.) Sm. y estando ausentes los pteridófitos endémicos eumediterráneos de origen neógeno.

La Pteridoflora del Gurugú está dominada por elementos submediterráneos $(52,94 \%)$ -distribuidos ampliamente en la región Mediterránea e incluso en zonas perimediterráneas donde encuentran refugio en nichos adecuados-, además de por elementos heterocóricos $(35,29 \%)$ - de extensa distribución en todo el mundo-, es decir el aspectro fitogeográfico (véase gráfico) está definido por pteridófitos que viven en grandes areales, pero los relictos paleomediterráneos $(11,76 \%)$ introducen un matiz de singularidad.

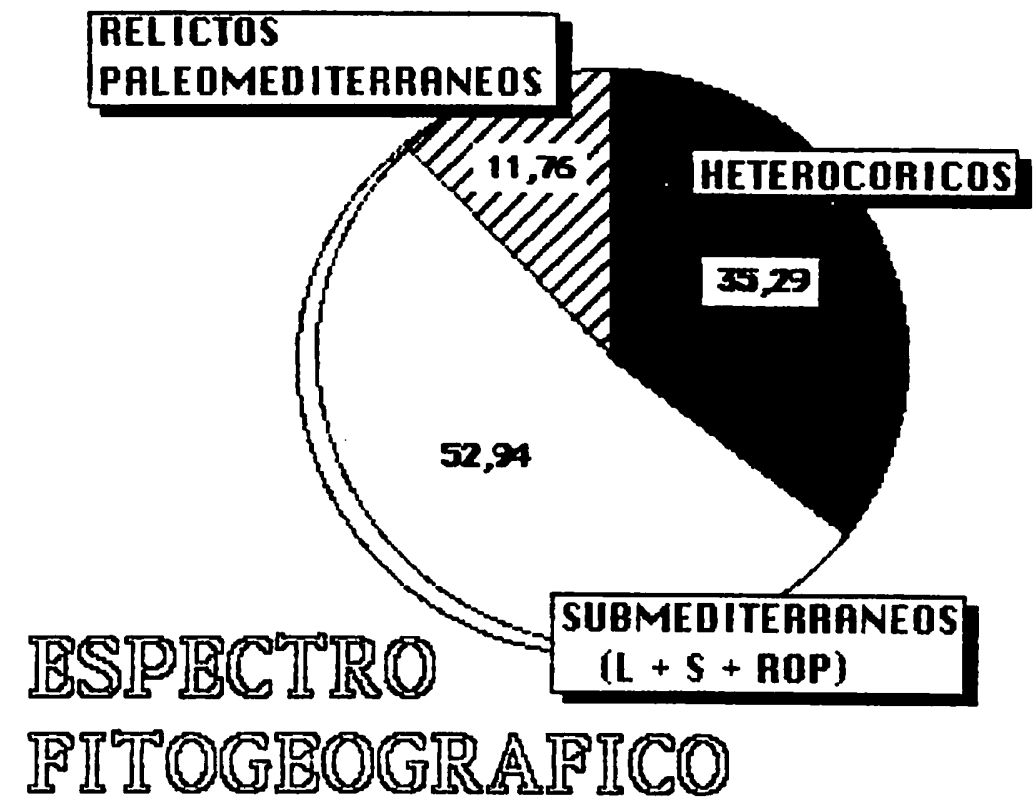


Durante el Mioceno, las condiciones de termicidad y humedad que caracterizaron los ambientes mediterráneos, permitieron el desarrollo de una flora tropical que en la actualidad ha quedado relegada de forma muy puntual. $D$. canariensis y $A$. hemionitis son dos helechos del Gurugú que participarón en esa flora Thética miocénica. Actualmente se encuentran distribuidos en los archipiélagos macaronésicos, Norte de Africa (Gurugú, Península Tingitana) y en la Península Ibérica: Sierra de Sintra en el caso de A. hemionitis y Galicia, Asturias y Sierras del Campo de Gibraltar en el caso de $D$. canariensis.

El emplazamiento de los archipiélagos macaronésicos respecto a las placas continentales durante el Mioceno, permitió el establecimiento de una vía migratoria florística sureuropea-norteafricana-macaronésica, que fue seguida por aquellos táxones que sufrieron un proceso de especiación en la región mediterránea durante el Mioceno. Como consecuencia de los cataclismos y cambios ambientales generales que tuvieron lugar posteriormente a lo largo del Cuaternario, estos elementos de origen mediterráneo quedaron confinados en aquellas estaciones donde las condiciones ecosistemáticas estaban más cercanas a las que reinaron en la región mediterránea a lo largo del Mioceno: estaciones cálidas y húmedas. De este modo, hoy aquellos pteridófitos viven en ambientes atlánticos (Macaronesia, Galicia, Asturias) estando presentes también en algunos enclaves mediterráneos de los que originariamente ocuparon en su expansión miocénica, como las Sierras de Algeciras o el Macizo del Gurugú para el caso de $D$. canariensis y $A$. hemionitis.

Se deduce nuevamente a partir de aquí la importancia del Gurugú como albergue terciario.

Precisamente al evaluar la pteridoflora del Gurugú mediante el Indice de Similitud con las Regiones Próximas (ISRP) (SALVO \& CABEZUDO, 1984), (véase Lámina 10), nos encontramos que de todas las localidades estudiadas, el Gurugú presenta un carácter más atlántico que mediterráneo; determinado indudablemente por la presencia de táxones como los citados anteriormente.

El mismo efecto se produce al utilizar un Indice de Similitud como el de SORENSEN (1948), manifestándose una mayor semejanza con las pteridofloras de los OGUs más próximos al Estrecho de Gibraltar que respecto a los más alejados del mismo, de entre todos los elegidos en el análisis comparativo.

Finalmente apuntar que en el análisis de estas especulaciones pteridogeográficas, se debe incluir toda cuanta información sea comparable en términos homogéneos para los distintos OGUs. En el sucinto análisis anteriormente expuesto, la evaluación pteridoflorística se ha basado casi con exclusividad en datos relativos a la presencia/ausencia de las especies pteridofíticas que viven en esas localidades, no obstante se prevee como deseable y necesario el poder manejar datos relativos a :

- La frecuencia de aparición de los táxones (ausente, muy raro, raro, ocasional, frecuente $o$ abundante).

- La ecología: autoecología y sinecología para los distintos ecosistemas y localidades, incluyendo los espectros fitocenológico (porcentajes de aparición en hábitats diferentes tipificados previamente) y edáfico (porcentajes de presencia en sustratos acidófilos, basófilos o neutrófilos).

- El espectro biológico (porcentaje de aparición de biotipos tipificados previamen- 


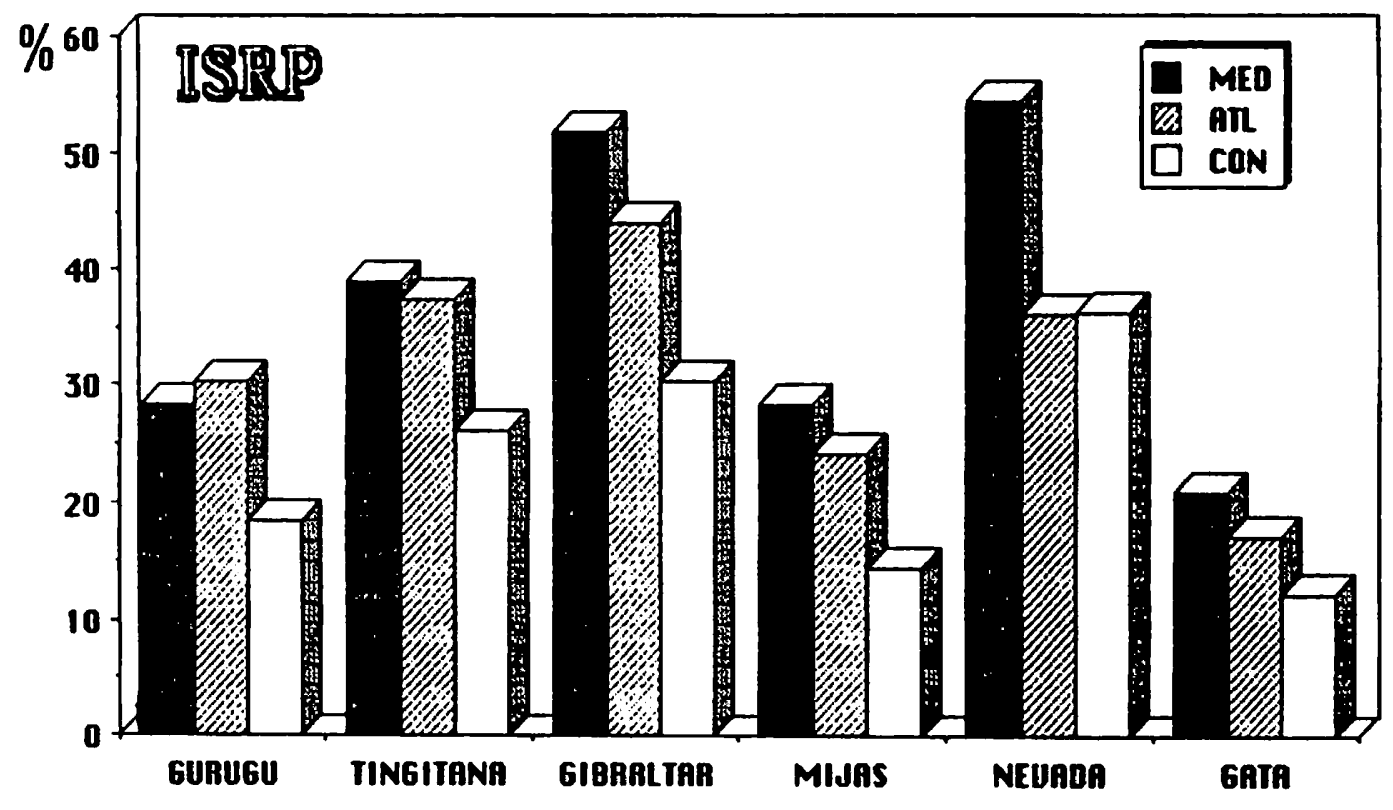

\section{LAMINA 10}

Histograma de frecuencias según los valores obtenidos por aplicación del ISRP (Indice de Similitud con las Regiones Próximas) para los distintos OGUs (Unidades Geográficas Operativas) estudiados.

El ISRP (SALVO y CABEZUDO, 1984) resulta de la aplicación del Coeficiente de Similitud de SÖRENSEN (1948) para las pteridofloras estudiadas respecto a las de las regiones Mediterránea (MED), Macaronésica (ATL) y Eurosiberiana (CON), donde existen respectivamente 103, 82 y 136 especies de pteridofitos.

La expresión del Coeficiente de Similitud de SÖRENSEN (op. cit.) es:

$$
Q=\frac{2 z}{x+y} \cdot 100
$$

donde

$\mathrm{z}=$ número de especies comunes entre las zonas a comparar (zonas $\mathrm{A}$ y $\mathrm{B}$ ).

$\mathbf{X}=$ número de especies que componen la pteridoflora de la región $\mathbf{A}$.

$y=$ número de especies que componen la pteridoflora de la región $B$. 
te).

- El cómputo de categorias subespecíficas y los complejos de hibridación.

- El espectro de los niveles ploídicos (atlas cromosómico).

— La evaluación de las amenazas.

No obstante, cuando se trabaja con grandes áreas desigualmente estudiadas para cada uno de los OGUs que en ellas puedan seleccionarse, el acceso a tales datos es dificultoso, por lo que se ha de recurrir sólo a aquéllos que puedan compararse homogéneamente por ser semejante el nivel de información que de ellos se posee para los diversos OGUs investigados.

\section{4.- Los helechos y el hombre: el reto proteccionista}

En todo el mundo se está asistiendo a un progresivo y parece que imparable proceso degradativo del mundo natural. Dentro de esta idea general, la situación se torna por momentos en realmente crítica para el caso de los helechos.

Los ecosistemas donde viven están siendo deteriorados de forma irreversible por una inadecuada gestión y abusivo aprovechamiento humano de los recursos naturales que ofrecen dichos sistemas.

El mundo mediterráneo, determinado históricamente por la presencia del hombre desde muy antiguo, ha sido testigo de su propia regresión natural promovida por la controvertida acción antrópica en sus asentamientos territoriales y con proyección hacia los ambientes circundantes. No obstante ha conservado de forma suficientemente representativa esa riqueza natural que define su especial sigularidad respecto a otras regiones del planeta.

Su valiosa flora ha estado tradicionalmente afectada de forma directa por las actividades humanas y el auge y expansión de sus asentamientos, por otro lado ha contribuido decisivamente al desarrollo y progreso de éstos, en un marco de relación por necesidad. Relación que el tiempo dejó sentir, por haberse establecido desde un principio y continuado posteriormente sobre la base del desequilibrio: una relación basada en la explotación indiscriminada de los recursos y en ulteriores intentos irracionales, desconectados y puntuales de recuperación de dicho patrimonio, traducidos de ordinario como intentos negativos.

La salvaguarda real y efectiva de la riqueza florística mediterránea es una labor todavía pendiente; el Sur Ibérico y el Norte de Africa son zonas que no se exceptúan de este aserto y cuya transcendencia en la historia de la flora mediterránea parece no dejar dudas acerca de su necesaria protección.

Los pteridófitos, de entre todos los elementos protegibles de nuestra flora, debieran ser objeto, si cabe, de un tratamiento proteccionista excepcional; utilizando como argumento justificativo de esta propuesta la dependencia tan estrecha que en repetidas ocasiones presentan respecto a los ecosistemas donde viven, dcbiéndose conservar y proteger la integridad de los mismos que, además de constituir unos valiosos y a veces únicos emplazamientos para los elementos vivos que integran su estructura, son testimonio vivo de los ambientes naturales del pasado (ecosistemas relícticos) en muchos casos. 
El público en general mantiene un conocimiento relativamente pobre y cuando menos superficial de los helechos, sobre todo en lo concerniente a su vida en la Naturaleza, siendo más populares las variedades utilizadas comercialmente por su valor ornamental.

En otro sentido, el hombre tampoco ha utilizado con frecuencia estas plantas para su propio beneficio, a pesar de haberles sido atribuidas algunas propiedades curativas y reconocido algunos valores farmacológicos.

Ciertas causas podrian apoyar este hecho; pues fuera de la áreas intertropicales, los helechos quedan relegados generalmente en lugares de difícil acceso y frecuentemente alejados de los núcleos humanos, por otra parte y a pesar de que tododavía queda por conocer a fondo la fitoquímica de los productos naturales en pteridófitos, lo cierto es que dada su antigüedad y al mantenerse evolutivamente al margen de procesos coevolutivos con animales que interviniesen en su diáspora, como otros grupos vegetales llevaron a cabo, entre sus componentes químicos abundan las sustancias oncogénicas y avitamínicas. No obstante los helechos han sido relativamente algo utilizados por la medicina popular. Deteniéndonos en el caso de la pteridoflora que más de cerca hemos visto, la del Gurugú, podríamos realizar una breve reseña de las propiedades medicinales otorgadas a esos vegetales. Asi Selaginella denticulata (L.) Spring ha sido empleada como antihelmíntico. O los equisetos ("colas de caballo") por ejemplo, dado su contenido en sílice (ácido silícico en disolución) eran considerados como excelentes diuréticos y se les atribuían también propiedades hemostáticas por la presencia de algunos ácidos. Otro helecho bastante apreciado por sus propiedades diuréticas fue el "helecho real", Osmunda regalis L., utilizándose su rizoma en distintos preparados. La "cabriña" o "calaguala", Davallia canariensis (L.) Sm., fue consumida muy abundantemente a principios de siglo siguiendo la moda que se extendió en aquel tiempo sobre la utilización de la "calaguala americana" o "calaguala del Perú" por sus virtudes sudoríficas y febrífugas, creyéndose útil contra las enfermedades venéreas. El rizoma de Polypodium cambricum L., por su altos contenidos en sustancias reservorias, ha sido bastante apreciado como purgante y como reconstituyente de enfermos con función hepática insuficiente, entre otros empleos medicinales. Como astringente, diurético y contra la tos, fue utilizado ampliamente Asplenium caterach L., además de otras especies de aspleniáceas. Pero de entre todos los componentes de la flora pteridofítica del Gurugú, que sepamos sólo el "culantrillo de pozo" (el "kousbouret el bir" o el "sak el kaal"de los rifeños), Adiantum capillus-veneris L., helecho que también podemos encontrar en Melilla a la altura de la Punta de Rostrogordo- ha sido más o menos utilizado por los lugareños, aprovechando sus propiedades para combatir la tos y el catarro, administrándose como tisana -al igual que Asplenium trichomanes L.-; la tisana de "culantrillo" fue también empleada para facilitar las menstruaciones dolorosas y regularlas en su caso. Su epíteto específico (capillus-veneris) se relaciona con el aspecto de cabellera que ofrecen los pecíolos de sus frondes deshojadas (cabello de Venus), habiéndose utilizado para remediar -infructuosamente— la caída del cabello.

\section{Las amenazas.}

Cuando se hace apología de una causa en la que se cree firmemente, la reiteración 


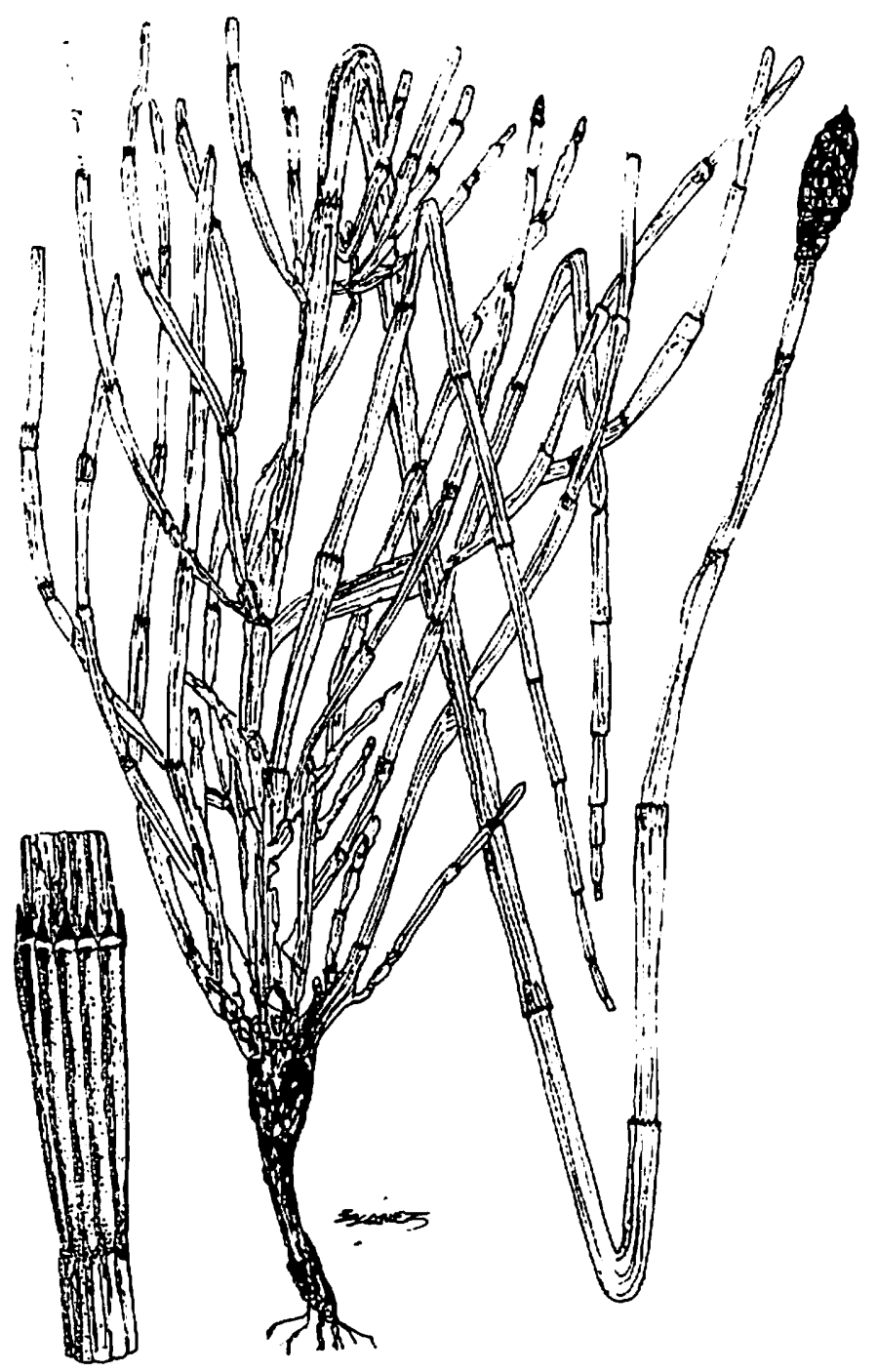

\section{LAMINA 11}

Hippochaete ramosissima (Desf.) Bruhin

"Cola de caballo".

Hábito del vástago aéreo y detalle de un nudo con su vaina. 
parece incluso obligada; por ello retomemos el tema de lo que se ha dado en llamar "erosión genética" (pérdida paulatina de las especies).

Los pueblos y culturas que sucesivamente colonizaron nuestra tierra desde antaño, han ido agravando la situación de la flora, ejerciendo numerosos impactos sobre la propia flora, la vegetación y los recursos forestales, con resultados tan desalentadores como la desaparición definitiva de algunas especies vegetales que no han podido conocerse vivas en la actualidad, desapareciendo de este modo una información genética que por su propia originalidad, calificable de única o irrepetible, supone una pérdida cuyo enorme valor es incalculable.

A pesar de ello, poco se puede o se quiere remediar esta situación puesto que la acción humana sigue constituyendo el impacto más devastador que amenaza la conservación de los recursos genéticos vegetales y animales por añadidura, en definitiva, que amenaza la herencia natural de nuestra tierra.

Muchas y diversas son las causas que hacen peligrar a las poblaciones vegetales, en general trasladables a distintas partes del mundo. En los últimos años han aparecido varias sintesis donde se computan ordenada y jerarquizadamente las diferentes causas que afectan negativamente al normal desarrollo de las poblaciones vegetales en su hábitats naturales, como las propuestas por el Consejo de Europa en su "Liste de plantes rares, menacées et endemiques en Europe" (1977), por GREUTER (1979) o por FILIPELLO (1981), que en conjunto clasifican los riesgos presumibles en cuatro apartados:

1.- Causas derivadas de procesos naturales.

2.- Causas derivadas del uso o disfrute de la flora espontánea.

3.- Causas derivadas de la humanización del territorio.

4.- Incendios.

En los helechos mediterráneos, las causas más determinantes de su regresión están provocadas por la desaparición de sus ambientes naturales como consecuencia de talas indiscriminadas de bosques (continuan desapareciendo dehesas de encinas, alcornoques y quejigos), un uso del suelo aleatorio y descontrolado sin ningún planteamiento de previsión, repoblaciones forestales desmesuradas con especies vegetales alóctonas pretendiendo objetivos estrictamente económicos que a veces rozan lo absurdo y cuando menos lo paradójico, dado que, al margen ya de la repoblación con estas especies alóctonas que conducen inevitablemente al desequilibrio de las condiciones óptimas del sustrato para el sustento de su vida natural y la consiguiente irreversibilidad del proceso a largo plazo, se están destruyendo unos ecosistemas de gran valor cultural, científico y paisajístico, e incluso económico si racionalmente se aprovecharan sus recursos atendiendo controladamente a unos programas de planificación elaborados por equipos multidisciplinares de profesionales expertos en el tema.

El ejemplo lo tenemos muy cerca de nosotros, en el Macizo del Gurugú, donde aún hoy se están continuando las explotaciones madereras de eucaliptos y nuevas plantaciones de pinos y eucaliptos.

Pero es que además, el crecimiento desbordante de los núcleos urbanos e industriales en muchas partes del mundo y la presión antrópica, siguiendo la tendencia de un mayor uso recreativo de los espacios naturales, sobre los escasos lugares privilegiados que aún 
hoy persisten y conservan unos condicionamientos ecológicos muy particulares (por ser precisamente los ecosistemas originales de dichas zonas), atentan contra el frágil equilibrio de su existencia y mantenimiento.

Los helechos del Gurugú y en definitiva todo el macizo, deberían gozar de una protección íntegra fácilmente deducible de las actividades humanas que allí se realizan: las ya mencionadas explotaciones de especies forestales alóctonas, el uso del entorno para el esparcimiento y recreo, el pastoreo, la agricultura en pequeñas parcelas arrebatadas a la estructura natural que son prácticamente "construidas" por los lugareños como pequeñas terrazas incluso en las escarpadas pendientes de los barrancos (como en el Barranco del Lobo por ejemplo). Muchos de estos helechos en otras regiones, por su abundancia, no sólo están desprotegidos, sino que además son objeto de numerosos intentos de erradicación, como el caso de un tipo de "cola de caballo" que se da en el Gurugú: Hippochaete ramosissima (Desf.) Bruhin, considerado por los agricultores sureuropeos como una mala hierba muchas veces difícil de eliminar, o el caso del "helecho águila", Pteridium aquilinum (L.) Kuhn, que por la profundidad de su rizoma y las extensas coberturas que ocupan sus poblaciones, careciendo de compctidores, impide la utilización del suelo para otros fines, agrícolas por ejemplo o para pasto del ganado, habiendo colonizado extensos pastizales en la Europa atlántica, ya irrecuperables para la explotación ganadera.

No obstante en nuestras latitudes y particularizando para el Macizo del Gurugú, estas mismas especies deberían protegerse por su escasez, estando localizadas de forma muy precisa, y por no aparecer en otros lugares hasta bastante kilómetros a la redonda.

Por lo demás, el resto de los pteridófitos del Gurugú son en su mayoría hemicriptófitos rizomatosos y casmocomófitos o casmófitos, raramente epífitos (sólo $P$. cambricum y $D$. canariensis), encontrando pues en los barrancos y en las grietas de las rocas volcánicas presentes allí, el medio adecuado para su desarrollo.

El "culantrillo de pozo", A. capillus-veneris, suele vivir en las fisuras de rocas calizas rezumantes, normalmente dispuestas a lo largo de los pequeños riachuelos y torrenteras que surcan los barrancos del macizo. En las comunidades briopteridofíticas desarrolladas en dichos lugares abundan también $S$. denticulata y Anogramma leptophylla (L.) Link.

Los equisetos, "colas de caballo", requieren condiciones de alta humedad edáfica y umbría, debiendo estar su ecología determinada precisamente a lo largo de esos pequeños riachuelos que si bien no constituyen flujos permanentes de agua, si presentan a lo largo de su recorrido pequeños charcos que suelen permanecer largo tiempo tras las lluvias, y que son utilizados para el aseo personal y el lavado de ropas y otros utensilios por quienes viven en la zona, convirtiéndose en verdaderos cúmulos de aguas putrefactas y pestilentes que contribuyen a la eutrofización de todo el entorno.

Esta situación puede provocar la desaparición de $O$. regalis, el "helecho real", del que sólo hemos podido detectar unos diez ejemplares que viven protegidos en estos ambientes húmedos, requiriendo unos condicionamientos muy precisos que varían en un rango muy estrecho, tratándose de un helecho hidrófilo, esciófilo, termófilo y acidófilo.

Las aspleniáceas: Asplenium billotii F.W. Schultz, A. onopteris L., A. marinum L., A. trichomanes L., A. ceterach L. y A. hemionitis L., se comportan como especies 


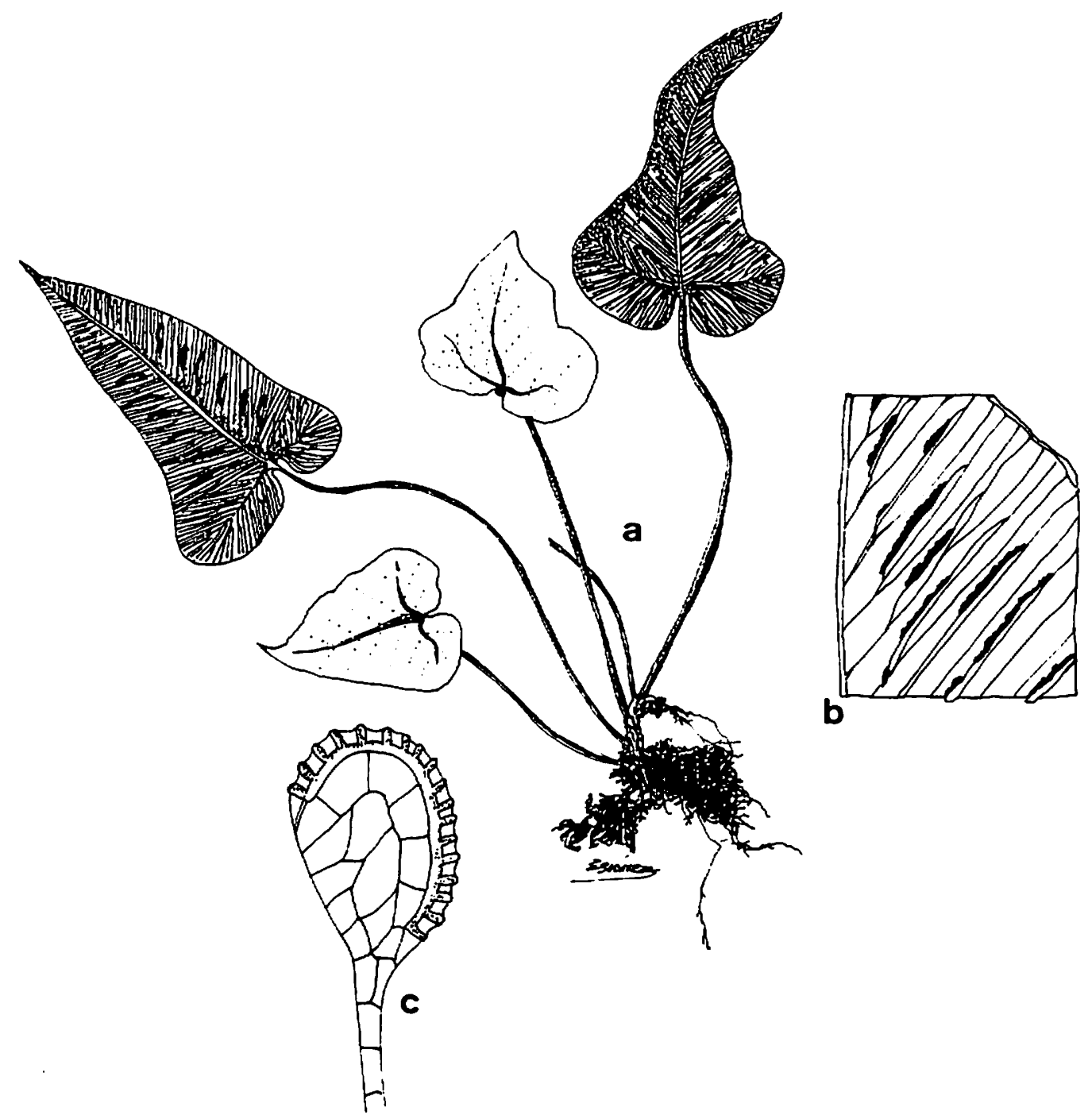

\section{LAMINA 12}

Asplenium hemionitis L.

a, hábito de la planta; b, detalle del envés de la lámina mostrando los soros a lo largo de las nerviaciones; c, esporangio. 
rupícolas en términos generales, cada una con sus especiales peculiaridades ambientales, destacando $A$. hemionitis por su excepcional valor biogeográfico y por la rareza con que aparece en el Gurugú (sólo hemos encontrado un ejemplar aislado en Takoben Iasinen, en la parte NE del macizo, donde abundantes rocas andesíticas de diverso tamaño se disponen en una rambla en la que el ambiente es muy xérico sin apenas dejar ocasión para la formación de suclo y con ausencia de cobertura vegetal, apareciendo ese único ejemplar en la base de una gran roca, con suelo escaso y con una cierta hemedad y umbria).

\section{Perspectivas de presente y de futuro}

En España apareció en 1982 el Real Decreto 3.091 de 15 de octubre (BOE № 280, 22.XI. 1982) sobre "Especies amenazadas de la Flora Silvestre", donde se protegían para todo el territorio nacional las especies incluidas en el Convenio de Berna de 1979; en el texto de dicho convenio sólo dos helechos se incluían: Diplazium caudatum (Cav.) Jermy y Pteris incompleta Cav. ${ }^{3}$, estimándose más tarde en nuestro país que de las aproximadamente 115 especies de pteridófitos que viven en la península Ibérica y Baleares, al menos 20 estarían amenazadas en distinto grado.

En 1986 (BOE № 235, 1.IX.1986) se publicaba por Jefatura del Estado el Instrumento de Ratificación de dicho convenio relativo a la "Conservación de la vida silvestre y el medio ambiente en Europa", elaborado en Berna en 1979 (Consejo de Europa $\left.\mathrm{N}^{2} 104\right)$.

El Convenio de Berna significó una decisiva toma de conciencia y gestión en la protección de la flora internacional, que tuvo su antecedente en una propuesta anterior del propio Consejo de Europa en 1977, la citada más atrás "Liste de plantes rares, menacées et endemiques en Europe", y provocó el impulso de toda esa corriente de opinión "ambientalista" y "proteccionista" que se fue gestando desde la Conferencia de Estocolmo sobre el Medio Ambiente en 1972. No obstante, el propio dinamismo de la vida vegetal queda manifiesto en estos listados, que deberían abordarse y concebirse igualmente como dinámicos y cambiantes, y no como una lista estática y perfecta. Tradicionalmente las posturas adoptadas frente a estas relaciones de especies vegetales, han sido poco originales, circunscribiéndose fundamentalmente a medidas puntuales y desconectadas, con una visión que nunca ha ido más allá de los límites del propio listado. Lo cierto es que textos como el Convenio de Berna, padecen un inevitable pero a su vez indeseable anacronismo entre el momento en que son

(3) A principios de 1988 nos fue concedida una de las tres ayudas a la Investigación sobre el Medio Ambiente Andaluz (Agencia del Medio Ambiente, Junta de Andalucía), gracias a la cual pudimos poner en marcha nuestro proyecto de investigación que se centró en el estudio de estos dos helechos y otras dos especies vegetales de fanerógamas ibero-mauritanas, cuyo título fue: "Proyecto Nostrum, un modelo para el conocimiento y experimentación con especies vegetales relicticas y endémicas. Profundización en el conocimiento de la biología de Diplaziun caudalum (Cav.) Jermy; Pteris incompleta Cav.; Rupicapnos africana (Lam.) pomel y Atropa baetica Willk.; especics de la flora andaluza estrictamente protegidas e inscritas en el Convenio de Bema de 1979". 
elaborados y propuestos hasta que son finalmente aprobados y se ponen en marcha acciones concretas para su gestión.

En nuestro país se permitía en la primera disposición legal relativa a la protección de especies vegetales —el anteriormente mencionado Real Decreto de $1982-$, la libre intervención de las Comunidades Autónomas para la ampliación y concreción del listado.

Posteriormente por Orden Ministerial 22112 de 17.IX.1984 se amplió el listado de aquel primer Real Decreto con otras especies vegetales baleáricas. A pesar de todo, la definición de competencias ente Organismos c Instituciones de la Administración y lo aparentemente complejo del problema han ocasionado durante bastante tiempo la ausencia importante de una normativa legal eficiente y ajustada a la realidad.

Siguiendo esta línea de gestión política de la Naturaleza, la Agencia de Medio Ambiente de la Junta de Andalucía (A.M.A., 1987) elabora una propuesta de protección de la flora regional andaluza, tomando como base los listados ibéricos de especies vegetales susceptibles de protección y adecuándolos a Andalucía con la inclusión de nuevos táxones, con especial dedicación a los endemismos regionales y locales, incluyendo 9 especies distintas de pteridófitos. Para Marruecos desconocemos que exista alguna legislación tendente a proteger las especies vegetales, siendo ésta urgente y necesaria, y además muy importante para la flora ibérica y particularmente andaluza, por el gran número de endemismos ibero-mauritanos que comparten ambos territorios - precisándose medidas de protección y conservación coordinadas entre países riberefios del Mediterráneo- como nuestro más cercano ejemplo de España y Marruecos; ya que de otra forma los esfuerzos que se realicen de una parte no podrán alcanzar los objetivos pretendidos o sólo parcialmente, si no existe la correspondencia de esfuerzos similares de la otra parte.

Al margen de lo puramente legislativo, en España varios botánicos pteridólogos vinculados a distintas universidades del país, crean en 1979 el Grupo Pteridológico Ibérico (GPI), presidido desde sus inicios por el Dr. S. RIVAS-MARTINEZ de la Universidad Complutense de Madrid y cuya secretaría ha sido responsabilidad del Dr. A.E. SALVO, de la Universidad de Málaga.

Tres objetivos principales centraron las actividades del grupo desde su creación:

1.- Fomentar la investigación pteridológica y el contacto científico entre sus miembros.

2.- Divulgar los conocimientos pteridológicos dentro de la comunidad botánica.

3.- Trasmitir la cultura pteridológica y su preocupaciones a la sociedad.

A lo largo de estos años el grupo apoyó la organización de la "I Reunión Internacional de Pteridología" (Algeciras, 1980), los "I Coloquios Pteridológicos" (Madrid, 1984) o el reciente "Simposio sobre Taxonomía, Biogeografía y Conservación de Pteridófitos" (Mahón, 1988). El grupo impulsó además durante el "III Simposio de OPTIMA (Organization for the Phyto-Taxonomic Investigation of the Mediterranean Area)" (Madrid, 1980), la creación de la "Comission for Pteridophyta" de dicha organización.

La actividad científica volcada en el estudio de los pteridófitos pudo coordinarse con la ejecución conjunta de diversos proyectos realizados con la colaboración de los miembros del GPI:

— Exsiccata Pteridophyta Iberica. Proyecto iniciado en 1985 con un objetivo bien 


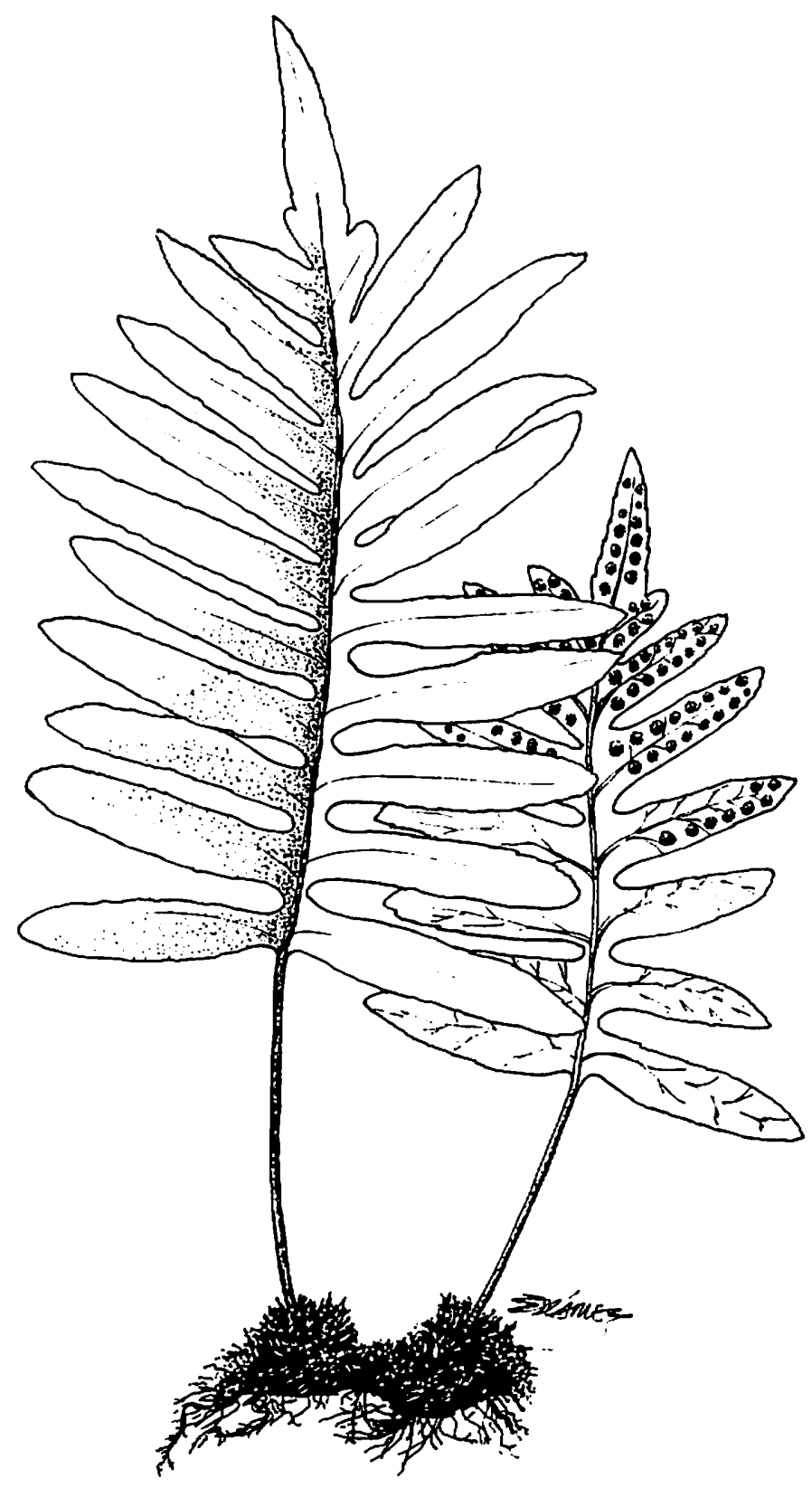

\section{LAMINA 13}

Polypodium cambricum L. Hábito de la planta. 
definido: que en todos los centros - universitarios en su mayoría - que participasen en el mismo (un total de 15 centros en la Exsiccata de 1988) se dispusiese del material recolectado por los demás, quedando recogidos en un pequeño boletín anual los datos corológicos y ecológicos de los táxones cedidos para este intercambio.

- Centro de Documentación Bibliográfica del GPI. Fondo bibliográfico con sede en el Departamento de Biología Vegetal I de la Universidad Complutense, con especial preferencia por aquellos trabajos publicados por los miembros del grupo.

- Libro rojo de los pteridófitos amenazados de la Península Ibérica. Contribución de distintos coordinadores regionales para la constitución de un Libro Rojo de los pteridófitos amenazados que ha venido teniendo su desarrollo bajo el diseño del llamado Proyecto Psilotum: "Lista de pteridófitos raros o amenazados de la España Peninsular e Islas Baleares".

- Atlas de la Pteridoflora Ibérica. Confección de un Atlas Pteridológico ibérico en cuadrícula UTM de $10 \mathrm{kms}$. $\times 10 \mathrm{kms}$.

- Campañas pteridológicas ibéricas. Reuniones anuales en un enclave pteridofítico interesante de la Península Ibérica para el estudio in situ de los pteridófitos, su distribución y comportamiento ecológico, asi como el estado de conservación de las poblaciones.

En definitiva, la pteridología española está viviendo momentos de esplendor al que contribuyen jóvenes investigadores, quienes desde un conocimiento científico profundo de estas plantas, defienden su conservación y protección.

Las propuestas de futuro tienden a acciones globalizadoras que agrupen y sinteticen las abundantes informaciones que se están derivando de las recientes investigaciones realizadas, por esta razón, los iniciales proyectos pteridológicos llevados cabo por miembros del GPI, tendrán su continuidad en el recién propuesto Proyecto AXIS, dirigido y concebido por el Dr. A.E.SALVO, a quien desde aquí nos atreveríamos a calificar como verdadero artífice de la Escuela Pteridológica Española. En dicho Proyecto AXIS (SALVO \& GARCIA-VERDUGO, 1988) quedarían ordenados en una base de datos informatizada, abierta y euritmica las informaciones recopiladas para las pteridofloras mediterráneo-occidental y macaronésica.

Se une así la pteridología española a la movilización internacional que se preocupa por los pteridófitos y su futuro (al menos en los ambientes científicos), expresada en programas como el "Plan para la Protección de los Pteridófitos" (1986) de IUCNIAP, desde donde se enumeraban una serie de medidas aconsejables como la creación de una base de datos sobre la biología general de las especies, su taxonomía y biogeografía; diseñada para la revisión continuada del status de dichas especies y de las amenazas que recaen sobre ellas; promoción de su propagación ex situ (proceso bastante común en algunos helechos por la utilización ornamental de varias especies y variedades) y de su propagación in situ (proceso necesario dentro de iniciativas globales destinadas a la conservación de los ecosistemas donde viven y dentro de programas destinados a la recuperación de estaciones degradadas que gozaron anteriormente de un ópitmo estado de conservación); fomento de múltiples enfoques científicos desde la distinta perspectiva ofrecida por las disciplinas de investigación biológica utilizadas para profundizar en el conocimiento de los pteridófitos, que permitan dis- 
poner de una información extensa y actualizable a fin de realizar la planificación, manejo y ordenación de los datos preexistentes y de los nuevos obtenidos, con su posterior análisis estadístico a través de tratamientos informatizados para la extracción de conclusiones generales.

Toda esta declaración de intenciones plasmada en una legislación coherente y en unos planteamientos científicos de conjunto, probablemente se pierda con el vacio si no se logra tratar el problema de la conservación y la protección de las especies desde los puntos básicos y decisivos que lo definen; éstos vienen a resumirse en un argumento cultural, educativo y de conciencia. La realidad es que la promulgación de normas legales surgidas desde las administraciones públicas de distintos países o los consejos que organizaciones internacionales de diversa índole dan a conocer continuamente, así como las rigurosas, crípticas y a veces inaccesibles investigaciones científicas, rara vez se dejan sentir en el gran público - a pesar de las agravantes sanciones que las leyes recogen para quien infringe las normas establecidas-; pero es que además, en quien recae la obligación de velar por el cumplimiento de estas normativas, existe a menudo una desinformación grande acerca de su propio cometido y responsabilidad, desconociendo en general qué hay que proteger, dónde y cómo.

Las especies vegetales deben ser, evidentemente, protegidas y por este motivo su recolección no debería realizarse bajo ningún concepto cuando se conozcan graves amenazas que pesen sobre su pervivencia, si bien móviles estrictamente científicos con finalidades relacionadas con su estudio para poder actuar más eficientemente en su conservación, son razones importantes como para permitir la recolección limitada y controlada de estas plantas, siempre desde el estricto cumplimiento de una ética profesional a veces descuidada, siendo en el propio seno de la comunidad científica botánica y entre los coleccionistas donde a veces abunda el desmesurado afán recolector de un material vivo que en ocasiones es de escasa o nula utilidad científica (reiterados ejemplares de una misma población o localidad ) y en cambio su permanencia en el hábitat natural puede ser decisiva, y más aún tratándose de especies cuyas poblaciones en no pocas ocasiones están constituidas por muy bajo número de ejemplares.

\section{Expresión de gratitud.}

Quiero dejar constancia de mi más sincero agradecimiento al Dr. A.E. SALVO por su continuo estímulo y ayuda, así como por ser él quien me introdujo en el entonces desconocido para mí, mundo de los helechos. Igualmente deseo agradecer a los conservadores de los herbarios del Deparamento de Biología Vegetal de la Universidad de Málaga y del Instiut Scientifique de Rabat, así como al Director del Colegio "La Salle-El Carmen" de Melilla, las facilidades otorgadas para el estudio del material alli depositado. Finalmente, dar las gracias a A. BARON y A. DEL SALTO por su infatigable paciencia en las excursiones que realizamos juntos por el Gurugú.

Dedicatoria.

A mis padres.

A mi abuela Isabel. 
AGENCIA DE MEDIO AMBIENTE (A.M.A.). JUNTA DE ANDALUCIA. 1987. Informe General del Medio Ambiente en Andalucía 1987. Sevilla.

ALCALA VARGAS, J.L. 1982. Estudio sobre el clima de Melilla. Excmo. Ayuntamiento de Melilla.

BOWER, F.O. 1923, 1926, 1928. The ferns, Vol. I, II, III. Camb. Univ. Press.

CABALLERO, A. 1915. Enumeración de las plantas herborizadas en el Rif. Mem. R. Soc. Esp. Hist. Nat., t. 8: 241-292.

CABALLERO, A. 1917. Excursión botánica a Melilla en 1915. Trab. Mus. Nac. Cienc. Nat. Madrid. Ser. Bot. $n^{2} 11,39$ pág.

CASTROVIEJO, S. et al. (eds.). 1986. Flora lbérica. l. Lycopodiaceae-Papaveraceae. Madrid.

CANDEL, R. 1931. Excursiones por Marruecos. Macizo del Gurugú. Africa agosio, pág. 151.

CASTILLO, A. \& A.E. SALVO. 1989. Análisis pteridogeográfico de los pteridófitos de la provincia de Almeria. Acta Bot. Malacitana 14. (En prensa).

C.P.M. 1977. Liste de plantes rares, menacées et endemiques en Europe. Conseil de l'Europe 14. Strasbourg.

DIEZ, B. \& A.E. SALVO. 1981. Ensayo biogeográfico de los pteridofitos de las sierras de Algeciras. Anales Jard. Bot. Madrid 37 (2): 455-462.

ENGLER A. \& K. PRANTL. 1898-1902. Die Natürlichen Pflanzenfamilien. Berlin.

ESCAMEZ, A.M. \& A.E. SALVO. 1988. Análisis comparativo fitogeográfico y ecológico de la pteridoflora del Macizo del Gurugú. Anales Jard. Bot. Madrid. (En prensa).

ESCAMEZ, A.M. 1988. Proyecto Nastrum. Un modelo para el conocimiento y experimentación con especies vegetales relicticas y endémicas. Profundización en el conocimiento de la biologla de Diplazium caudatum (Cav.) Jermy; Pteris incompleta Cav.; Rupicapnos africana (Lam.) Pomel y Atropa baetica Willk.; especies de la flora andaluza estrictamente protegidas $e$ inscritas en el Convenio de Berna de 1979". Agencia de Medio Ambiente. Junta de Andalucía. (Inédito).

FILIPELLO, S. 1981. Specie vegetali da proteggere: analisi delle cause di pericolo e motivazione degli interventi. Alti del Seminario sul tema "Problemi scientifici e tecnici della conservazione del patrimonio vegesale". Consiglio Nazionale delle Ricerche. Pavia.

FONT QUER, P. 1916. Sobre la flora de Melilla. Bol. R. Soc. Esp. Hist. Nat. t. 16: 285-287.

FONT QUER, P. 1962. Plantas medicinales. El Dioscórides renovado. Labor. Barcelona.

FONT QUER, P. 1965. Diccionario de Botánica. Labor. Barcelona.

GARCIA FIGUERAS, T. 1948. Los naturalistas españoles en Marruecos in Las ciencias naturales en el Africa Hespérica. Imp. del Majzen. Tetuán.

GIVEN, D. R. \& A. C. JERMY. 1985. Conservation of pteridophytes: a postcriph Proceedings of the Royal Society of Edinburg, 86 B: 435-437.

GOMEZ CAMPO, C. et al. 1987. Libro Rojo de especies vegetales amenazadas de España peninsular e Islas Baleares. ICONA. Madrid.

GREUTER, W. 1979 Mediterranean conservation as viewed by a plan taxonomist. Webbia 34: 87-89.

JAHANDIEZ, E. \& R. MAIRE. 1931. Catalogue des plantes du Maroc. I.. Alger.

JERMY, A. C. 1984. Origin and distribution of pleridophytes in the Mediterranean area. Webbia 38: 397-416.

LÖVE, A., D. LÖVE \& R.E.G. PICHI SERMOLLI. 1977. Cytotaxonomical Allas of the Pteridophyta. J. Cramer. Vaduz.

MAIRE, R. 1952. Flore de l'Afrique du Nord. I. Paris.

MANTON, L. 1950. Problems of cytology and evolution in the Pteridophyta. Camb. Univ. Press. Cambridge.

MAS Y GUINDAL, J. 1928. Labor de los botánicos españoles en el Protectorado de Marruecos. Boletín de Farmacia Militar 71: 348-353.

MAS Y GUINDAL, J. 1929. Impresiones de unos viajes por Melilla: Notas rápidas de minería, botánica y farmacología. El Telegrama del Rif, 8,9 y 10 de agosto.

MAS Y GUINDAL, J. 1930. Mis excursiones botánicas por la Zona de Melilla. Notas rápidas de un viaje. Mauritania, abril.p. 121.

MAS Y GUINDAL, J. 1930. Impresiones de un viaje por la Zona de Melilla. Notas rápidas de mineralogía, botánica y farmocognosia. Mauritania, julio, agosto y septiembre. pp. 204, 232, 279.

MAS Y GUINDAL, J. 1931. La misión cientifica Bolivar en Marruecos y nuestras recoleccciones de plantas. Madrid. 
MAS Y GUINDAL, J. 1934. Farmacognosia y terapéutica mora. Boletín de Farmacia Militar 136: 100-107.

NETO, J. M., B. CABEZUDO \& A.E. SALVO. 1987. Análisis pteridogeográfico de las Sierras de Tejeda y Almijara (Málaga-Granada, España), Acıa Bot. Malacisana 12: 103-110.

PAU, C. 1911. Una visita botánica al Rif. Annoes de Acad. polytechn. do Porto, t. 6, 4 pp.

PAU, C. 1918. Plantas de Melilla. Bol. Soc. Aragón de Ciencias Nat., pp. 123-133.

PAU, C. 1921. Una centuria de plantas del Rif oriental. Bol. R. Soc. Esp. Hist. Nat., t. 21 (4.5): 198-204.

PICHI SERMOLLI, R.E.G. 1972. An historical review of the higher classification of Filicopsida, in "Symposium on the phylogeny and classification of the Filicopsida". Springer-Verlag. New York.

PICHI SERMOLLI, R.E.G. 1977. Tentamen pteridophytorum genera in taxonomicum ordinem redigendi. Web. bia 31 (2): 313-512.

PICHI SERMOLLI, R.E.G. 1979. A survey of the pteridological flora of the Mediterranean Region. Webbia 34: 175-242.

PICHI SERMOLLI, R.E.G., L. ESPAÑA \& A.E. SALVO. 1988. El valor biogeográfico de la pteridoflora ibérica. Lazaroa. (en prensa).

PRELLI, R. 1985. Guide des Fougéres et plantes alliées. Lechevalier. Paris.

ROSELLO, J.A. \& A.E. SALVO. 1988. Análisis biogeográfico de la pteridoflora balear. (En prensa).

SALVO, A.E. 1982. Flora pteridofítica de Andalucia. Depto. Bot. Univ. Málaga.

SALVO, A.E. \& B. CABEZUDO. 1984. Bases para la utilización de los pteridófitos en el establecimiento de unidades corológicas, I. Andalucía. Anales de Biología (Murcia) I: 309-316.

SALVO, A.E. \& A.M. ESCAMEZ 1987. Boletín del Grupo Pteridológico Ibérico, in Exsiccata Pteridophy a Iberica 1987. Universidad de León.

SALVO, A.E. 1988. Biogeografia numérica en Pteridología. Actas del Simposio sobre Taxonomía, Biogeografía y Conservación de pteridófitos. Menorca. (En prensa).

SALVO, A.E. \& A.M. ESCAMEZ. 1988. Influenia del Estrecho de Gibraltar en el relictualismo de la flora pteridofítica de sus zonas adyacentes: análisis pteridogeográfico. Actas del Congreso Internacional sobre El Estrecho de Gibrallar. UNED. Ceuta.

SALVO, A.E. A. FLORES \& A.M. ESCAMEZ 1989. El origen de los cormófitos. Transmigración y colonización terrestre. Publicaciones del Centro Asociado a la UNED de Melilla, n. 12 . (En Prensa).

SALVO, A.E. \& J.C. GARCIA-VERDUGO. 1988. Proyecto AXIS. Aplicación de una base de datos al estudio biogeográfico de los pteridófitos del Mediterráneo Occidental e Islas Macaronésicas. Actas del Simposio sobre Taxonomia, Biogeografía y Conservación de Pleridófitos. Menorca. (En prensa).

SALVO, A.E., J.M. NIETO \& B. CABEZUDO. 1989. El valor de los pieridófitos en la caracterización de los pisos bioclimáticos. (En prensa).

SENNEN \& MAURICTO, EE.CC. 1934. Catalogo de la Flora del Rif Oriental y principalmente de las cábilas lindantes con Melilla. La Ibérica. Melilla.

SENNEN, F. 1936. Campagnes botaniques du Maroc Oriental de 1930 d 1935 des Frères Sennen et Mauricio, EE.CC. Juan Bravo. Madrid.

SÖRENSEN, T. 1948. A method stablishing groupse of equal amplitude in plant sociology based on similarity of species content. Biol. Skr. (K. Dansk. Vidensk. Selsk.) 5: 1-34.

VARO, J. \& A.E. SALVO. 1982. Ensayo biogeográfico sobre los pteridófitos de Sierra Nevada (Granada, España). Acta Bot. Malacilana 7: 203-210.

VALDES, B., S. TALAVERA \& E. FERNANDEZ. GALIANO (eds.) 1987. Flora Vascular de Andalucía Occidental $l$.. Barcelona. 